\title{
LAS IDEAS PEDAGÓGICAS DE TOLSTOI Y TAGORE EN EL PROYECTO VASCONCELISTA DE EDUCACIÓN, $1921-1964^{1}$
}

\author{
Fabio Moraga Valle \\ Universidad Nacional Autónoma de México
}

\begin{abstract}
LA ETAPA MÍTICA: CREACIÓN Y EXPANSIÓN
DE UN SISTEMA EDUCATIVO, 1921-1924
\end{abstract}

\begin{abstract}
A inicios de 1928, durante el gobierno de Plutarco Elías Calles, la directora del Departamen1 to de Bibliotecas, Esperanza Velázquez Bringas, encontró en Chinautla, Puebla, después de muchos días de
\end{abstract}

Fecha de recepción: 30 de julio de 2014

Fecha de aceptación: 27 de febrero de 2015

${ }^{1}$ Un avance de este trabajo fue presentado en el seminario Justicia Social, Inclusión y Equidad en la Educación en México, del Instituto de Investigaciones sobre la Universidad y la Educación, IIsUe, de la UNAM, el 16 de junio de 2014. Otro en el XVII Congreso Internacional de la AHILA, en la Freie Universität de Berlín, en septiembre de 2014. El artículo es parte del proyecto "Inclusión y exclusión social en el desarrollo del Sistema Educativo Nacional. Organización, cobertura y financiamiento (1921-1964)", que el autor desarrolla en el IIsUe. Asimismo, deseo agradecer los sagaces comentarios de dos dictaminadores anónimos, que traté de seguir en su totalidad. 
camino, "unos Evangelios, una obra de Tolstoi, y un bello libro de Tagore”. ¿Qué hacían allí estos libros? ¿Por qué estaban en una biblioteca escolar pobre, rural y aislada en una zona montañosa en el centro de México? Una respuesta sería comprobar que habían llegado allí durante la campaña de creación de bibliotecas que distribuyó los llamados "libros verdes", que el secretario de Educación, José Vasconcelos, impulsó al frente de esa dependencia entre 1922 y 1924. Pero, ¿por qué el ateneísta y político había elegido precisamente esos autores (entre muchos otros) para constituir bibliotecas populares en todo México, incluso en regiones tan remotas como esa, donde los problemas cotidianos de sobrevivencia de la población no les permitirían apreciar literatura tan sofisticada? ¿Qué relación existía entre ese libro cristiano, la obra literaria de un escritor anarquista ruso y el trabajo de un escritor hindú, para que significaran algo para esos niños a los que estaban destinados?

El 3 de octubre de 1921, un decreto del presidente de México, Álvaro Obregón, creó la Secretaría de Educación Pública, sEP; con ello se buscaba articular la formación de un sistema público de educación con un proyecto de nación que debía surgir después de diez años de guerra revolucionaria. Los desafíos de entonces eran máximos: dar un fuerte impulso a la educación primaria para, con ello, alfabetizar a alrededor de $80 \%$ de los 15000000 de mexicanos, mayoritariamente población rural e indígena, que no sabía leer ni escribir y que vivían aislados en comunidades pequeñas; todo, con el fin de integrarla a la nación

${ }^{2}$ Boletín Bibliográfico, viI (mayo 1928), p. 201. 
respetando las diferencias culturales, lingüísticas y sociales que existían. ${ }^{3}$

Para lograr estos ambiciosos propósitos una de las primeras tareas era "federalizar” la educación, centralizándola en el Estado federal, con el fin de implementar un programa coherente y masivo de enseñanza:

La reforma constitucional que permitió la creación de la SEP no delimitó las funciones de la federación, ni emitió una ley que regulara las relaciones entre el orden federal y el local. Para federalizar la enseñanza, es decir, tener presencia en las diferentes entidades y brindarles recursos de la SEP, el secretario firmó convenios, subvencionó, creó, se apropió de instituciones o desarrolló una acción paralela a la de los estados. ${ }^{4}$

En todo este proceso fue clave la figura del intelectual y político José Vasconcelos, un abogado y filósofo educado en las postrimerías del porfiriato que formó parte de la llamada “generación del Centenario", en la que actuaron una serie de jóvenes agrupados en el Ateneo de la Juventud, un "cenáculo” de artistas e intelectuales unidos por su oposición al positivismo como cultura oficial del régimen de Porfirio Díaz (1876-1911). Pero los grandes objetivos que Vasconcelos -y sus cogeneracionales- tenían que resolver eran: cómo implementar un proyecto educativo de tal envergadura y

${ }^{3}$ Engracia Loyo ha entregado porcentajes disímiles de analfabetismo para esta época: mientras en un extenso trabajo habla de $80 \%$, en otro, más reciente y breve, sostiene que son $75 \%$; de todos modos son cifras alarmantemente altas. Loyo, Gobiernos revolucionarios, p. 124; Loyo, "La política educativa", p. 25.

${ }^{4}$ Loyo, "La política educativa", p. 25. VAsconcelos, Memorias, vol. II, El desastre y El proconsulado, pp. 52-57. 
llevar educación a un país geográficamente extenso y culturalmente diverso, lo que implicaba formular la pregunta: ${ }^{a}$ qué grandes ideas pedagógicas recurrir para ello?

Pese a que varias investigaciones se han ocupado de esto y que los mismos protagonistas dejaron abundantes huellas sobre su participación en esos años, hay aspectos que aún se desconocen, como los intercambios ideológicos entre Vasconcelos y su generación con intelectuales latinoamericanos (en especial argentinos, peruanos y chilenos) que coadyuvaron a la elaboración del proyecto vasconcelista de educación $y$ participaron en un nutrido intercambio intelectual que unió a México con otros países del continente. ${ }^{5}$

La mayoría de los trabajos sobre la generación del Centenario se han enfocado en la evidente influencia que sobre ésta tuvo la cultura griega clásica, que marcó buena parte del proyecto vasconcelista en la SEP y que se expresó concretamente en la publicación de los "libros verdes", de autores clásicos, en ediciones baratas, destinadas a la masa popular a la que se estaba alfabetizando. ${ }^{6}$ Por otra parte, la historiografía sobre la educación en México ha sostenido tradicionalmente que el teórico de la educación estadounidense John Dewey fue el principal ideólogo que inspiró la construcción del sistema educativo mexicano en esta época.

\footnotetext{
${ }^{5}$ Algunos de estos aspectos han sido tratados introductoriamente por YanKelevich, "La revolución de 1910", pp. 57-64. Otros, más recientes y específicos, han ahondado en los intercambios entre intelectuales conosureños y mexicanos; Moraga, "'Lo mejor de Chile está ahora en México"; y Melgar, "El epistolario".

6 Sobre la influencia clásica en la "generación del Centenario" véase Quintanilla, "Dioniso en México". Para los aspectos generales sobre la edición de los clásicos, Fell, José Vasconcelos.
} 
Augusto Santiago Sierra, al analizar el contenido del informe presidencial de Álvaro Obregón correspondiente a 1922, sostuvo:

De estas líneas presidenciales se desprende que ya los lineamientos de la educación mexicana habían adoptado los principios de la escuela de la acción, reforma que tenía como principal promotor en los Estados Unidos al filósofo pragmático John Dewey, que preconizaba una educación activa, dinámica y ajustada a la existencia misma de la comunidad.?

Investigaciones recientes como la de Bruno-Jofré y Martínez han analizado la "nation-building por medio de la incorporación/integración de la población indígena y rural mediante un contradictorio y ecléctico proyecto modernizador" gracias a la "recepción de las ideas de Dewey". ${ }^{8}$ Otros trabajos -no referidos directamente al tema educativo-, como el de Sosenski, han reafirmado esta idea al sostener que la "pedagogía de la acción de John Dewey" y la "educación socialista, tomada del ejemplo ruso", habrían guiado la "ecléctica práctica educativa mexicana” entre 1920 y 1940.9 Trabajos anteriores, como los de Loyo, han analizado la relación entre las propuestas de Vasconcelos y los planes educacionales implementados por Anatoli Lunacharski, ministro de Educación de la Rusia

\footnotetext{
7 Sierra, Las misiones culturales, pp. 14-15.

8 Bruno-Jofré y Martínez Valle, "Ruralizando a Dewey”, p. 46.

9 Sobre la presencia de las ideas de Dewey: Sosenski, "Niños limpios y trabajadores". Sobre la pedagogía activa, contamos con un texto fundamental, obra de una protagonista de la época: Guzmán, La escuela nueva o de la acción.
} 
soviética (1917-1929), durante los primeros años de la revolución rusa. ${ }^{10}$ Sin embargo, hay un aspecto clave, pero desconocido, del proceso de formación del sistema educativo mexicano durante estos años y que constituye nuestra hipótesis: la influencia más importante que tuvo Vasconcelos no provino ni de Lunacharski ni de Dewey, sino de dos educadores y reformadores sociales insospechados: el ruso León Tolstoi (1828-1910) y el indio (bengalí) Rabindranath Tagore (1861-1941). Ambos autores, normalmente reconocidos como escritores, casi desconocidos como educadores y menos aún como teóricos de la educación, fueron, además, creadores de sistemas educativos en sus respectivos países. ${ }^{11}$

En este artículo abordaremos cómo la influencia de esos autores ignorados estuvo presente durante más de cuatro décadas en el debate educativo del Estado mexicano, entre los años 1921 y 1965. Para ello analizaremos los cortos e intensos años que abarcaron la acción directa de Vasconcelos, primero, como rector de la Universidad Nacional (1920-1922), y luego como secretario de Educación Pública (1922-1924). En seguida, examinaremos qué aspectos de ese proyecto sobrevivieron a los continuos cambios de gobierno y de orientación política e ideológica y, finalmente, cómo el proyecto vasconcelista de educación fue retomado en las décadas posteriores por un discípulo y seguidor del filósofo, Jaime Torres Bodet, entre 1945 y 1965.

${ }^{10}$ Loyo, Gobiernos revolucionarios, p. 124. Véase también FeLl, José Vasconcelos, pp. 661-662.

11 Aunque, recientemente, los aportes de Tagore a la educación han sido destacados introductoriamente por los trabajos de MARTínez, "Entre Tagore y Gandhi”, y "Being, thinking and educating”. 


\section{UN INTELECTUAL Y UN PROYECTO ECLÉCTICO}

Lo que denominamos "proyecto vasconcelista de educación" fue un proyecto educativo elaborado por el intelectual mexicano José Vasconcelos quien se inspiró en lo que había hecho en Rusia el ministro de educación, Anatoli Lunacharski. Ideológicamente inspirado en un nacionalismo latinoamericanista, heredó la distinción entre el "norte pragmático" (Norteamérica sajona) y el sur idealista y espiritualista (América hispana), que había popularizado el intelectual uruguayo José Enrique Rodó en su obra Ariel desde 1900. ${ }^{12}$ Fue definido por el propio ministro como un "hispanismo constructivo y coherente" -que, por ello, molestó al gobierno estadounidense- y ejecutado durante los gobiernos posrevolucionarios de Rodolfo de la Huerta (1920) y Álvaro Obregón (1920-1924). ${ }^{13}$ Aunque Vasconcelos no actuó solo en la ejecución de este proyecto, sino que contó con la colaboración de varias generaciones de intelectuales mexicanos y latinoamericanos, lideró las iniciativas que fortalecieron la Universidad y su utilización para la "regeneración" moral y social del pueblo. Esto se tradujo en la formación de una Secretaría de Educación Pública que tuviera atribuciones en todo el país, por medio de una nueva ley de Educación. Dicha secretaría contaba con tres departamentos que abarcaban "todos los institutos de cultura": Escuelas,

${ }^{12}$ Rodó, Ariel. Aunque la idea de la contradicción cultural entre un norte "pragmático" y "materialista" contra un sur "espiritualista" o "idealista” habría sido divulgada en América Latina por el filósofo francés Ernest Renan y conocida por la cultura política liberal latinoamericana desde la década de 1860, fue el uruguayo quien quedó como su elaborador.

${ }^{13}$ Vasconcelos, Memorias. El desastre, p. 120. 
Bibliotecas y Bellas Artes. Las escuelas comprendían "toda la enseñanza científica y técnica en sus distintas ramas, tanto teóricas como prácticas". Bibliotecas fue concebido como "un complemento de la escuela". Bellas Artes tenía a su cargo la enseñanza del canto, el dibujo y la gimnasia en "todos los institutos de cultura artística superior", es decir, la antigua Academia de Bellas Artes, el Museo Nacional y los conservatorios de música. ${ }^{14}$

El mismo Vasconcelos no aclaró las corrientes ideológicas más profundas que inspiraron su proyecto de educación y la atención se desvió a la "influencia rusa". ${ }^{15}$ Por ello, hay aspectos que aún no se han investigado suficientemente. El primero, casi desconocido, tiene que ver con el origen de las ideas pedagógicas de Vasconcelos. En ellas el concepto clave es la "regeneración moral"; esta idea, que es la que guía su proyecto, aparentemente proviene de una concepción cristiana, que le habría inspirado la labor de los misioneros católicos (Pedro de Gante, Motolinía y Vasco de Quiroga), quienes evangelizaron México durante la colonia. La idea fundamental era la integración del indígena en un mismo sistema educativo y no la "educación especial” (separada entre indígenas y mestizos), todo lo contrario a lo que ensayó posteriormente el "callismo protestante" que creó escuelas especiales para indígenas. ${ }^{16}$

\footnotetext{
${ }^{14}$ Vasconcelos, Memorias. El desastre, p. 19.

15 En su momento, la relación entre la labor de Lunacharski y el proyecto del mexicano tampoco escapó a la atención de otros latinoamericanos como José Carlos Mariátegui, quien se apoyó en ella para hacer una crítica a la anquilosada academia peruana. Véase Mariátegui, "La crisis universitaria".

${ }^{16}$ Vasconcelos aclaró el origen y fundamento de las misiones culturales
} 
El segundo tiene que ver con un aspecto más estudiado sobre la generación del Centenario y que fue su fuerte crítica al positivismo y, como contrapartida, el cultivo preferente de aquella filosofía que negara al racionalismo que había caracterizado el desarrollo del pensamiento mexicano en el último tercio del siglo XIX. De esta manera, quienes lideraron la reflexión filosófica, Antonio Caso, Alfonso Reyes y el propio Vasconcelos, dedicaron esfuerzos no solo al estudio de la filosofía racionalista, sino también a las ideas de Nietzsche, Schopenhauer, Boutroux y al intuicionismo de Bergson. ${ }^{17}$

El tercero es la apertura de Vasconcelos a aportes culturales provenientes de regiones como Rusia e India, que se vieron reflejados en obras: El monismo estético (1918), Estudios indostánicos (1921), La raza cósmica (1925) e Indología (1926). Estos aspectos los tradujo a claves culturales cristianas e hispanoamericanas para aplicarlas a la realidad mexicana.

Todo lo anterior se reforzó cuando el ministro se rodeó de una serie de intelectuales y artistas que apoyaron su proyecto de "moralizar al pueblo" por medio de una concepción de la enseñanza popular, que promovía el intuicionismo, la educación libre y la centralidad del niño. La poetisa chilena Gabriela Mistral llegó a México en julio de

en sus memorias: VASCONCELOS, El desastre, pp. 123-124, y en su "Conferencia leída en el Continental Memorial Hall”, en Vasconcelos, Obras completas, t. II, p. 857.

17 Fernández Mac Gregor, Vasconcelos. En Historia del pensamiento filosófico (1937) Vasconcelos hizo un panorámico y ambicioso repaso de la historia de la filosofía desde sus orígenes, en los que, a diferencia de las versiones tradicionales, incluyó las filosofías de la India, China, Egipto y Judea. Véase Vasconcelos, "Historia del pensamiento filosófico", en Obras completas, t. IV, pp. 115-158. 
1922 y permaneció allí por dos años. ${ }^{18}$ Durante éstos, apoyó las Misiones Culturales (la iniciativa más rutilante del proyecto vasconcelista), habló directamente con los campesinos e indígenas, publicó libros de educación popular, asistió a congresos de maestros y campesinos e influyó en el texto de la ley de las misiones. ${ }^{19}$ Mistral era una atenta lectora de Tolstoi y Tagore, cuyas propuestas influyeron en su concepción pedagógica, que compartió entusiasta con Vasconcelos, así como su atracción por el vegetarianismo, la teosofía y la cultura oriental. ${ }^{20}$

18 Moraga, “'Lo mejor de Chile está ahora en México” ”, pp. 1193-1194. La estancia de Gabriela Mistral, al parecer, no respondió a un plan elaborado, sino más bien a la implementación, sobre la marcha, de la colaboración de intelectuales latinoamericanos en el proyecto vasconcelista, realizado gracias a los contactos del cuerpo diplomático mexicano. El hondureño Rafael Heliodoro Valle llegó a México en 1907 y tuvo una larga colaboración con este país, en el que vivió unos 50 años. El embajador en Chile, el escritor Enrique González Martínez, recomendó al ministro invitar a la chilena, y ella aceptó presurosa; mientras que Bernardo Gastellum, embajador en Uruguay, invitó a la poetisa Juana de Ibarbourou, aunque sin éxito. Mejor le fue a Vasconcelos con el líder estudiantil Haya de la Torre, al que invitó personalmente después de que los estudiantes de Trujillo lo proclamaran "maestro de la juventud" y que Vasconcelos, "a su pesar", tuviera que atacar al presidente Augusto B. Leguía por la represión desatada contra los jóvenes en mayo de 1923. De todos modos, la visita del peruano duró pocos meses (13 de noviembre de 1923 a 26 de mayo de 1924) y no alcanzó la relevancia que tuvo la colaboración de la chilena. Vasconcelos, El desastre, pp. 119-120. Melgar, Vivir el exilio en la ciudad, 1928 , p. 17.

19 "Proyecto para la organización de las misiones federales de educación", leído ante la Cámara de Diputados. Primera Comisión de Educación Pública, septiembre de 1923. Sierra, Las misiones culturales, p. 93. ${ }^{20}$ Hace casi medio siglo, investigadores como Marie-Lise Gazarian hicieron notar superficialmente los lazos que unen la concepción pedagógica de Gabriela Mistral con Rodó y Tagore: "Al resumir los conceptos que 
Trabajos como los de Bruno-Jofré y Martínez han distinguido acertadamente cuatro grandes corrientes pedagógicas presentes en la SEP en la década de 1920: la "populista-desarrollista”, representada por Moisés Sáenz; la "socialista”, encabezada por Narciso Bassols, secretario entre 1931 y 1934; la "anarquista-racionalista", con corifeos como José de la Luz Mena, quien no alcanzó puestos de poder en la SEP pero fue muy influyente en la llamada "educación socialista", y, finalmente, la de Vasconcelos, a la que sin mayor análisis denomina "espiritualista". Pero, ni por la relación con Mistral, ni por la fuerte impronta rodoniana en el proyecto vasconcelista de educación, es que estos autores la denominan así, sino "lamarquismo" que planteaba la mejora de los individuos y del conjunto de las razas. ${ }^{21}$

Pero, ¿ cómo dos intelectuales latinoamericanos, separados por miles de kilómetros, provenientes de dos naciones ubicadas en los extremos del continente y que vivieron experiencias políticas tan disímiles, pudieron coincidir en torno de la importancia fundamental que tuvieron para sus vidas y sus concepciones pedagógicas dos escritores -uno bengalí y otro ruso- separados por las mismas o más profundas brechas?

Gabriela Mistral tenía sobre la educación, se puede decir que pensaba que hay que enseñar con gracia a la manera de Rodó y de Tagore. Sólo de ese modo es posible inculcar el conocimiento y un sentido de responsabilidad moral y estética en el estudiante". GAzARIAN, "Gabriela Mistral como educadora”, p. 659. Posteriormente Vasconcelos rechazó la teosofía sosteniendo que "[...] la llamada Sociedad Teosófica, fundada por la señora Blavatsky en los Estados Unidos [...] jamás se había visto igual cinismo de charlatanería y de ignorancia como el que se muestra en cada una de las páginas de ese Isis sin Velo, La doctrina secreta, etc., etc.”. VAsConcelos, Estudios Indostánicos, en Obras completas, t. III, p. 133.

${ }^{21}$ Bruno-Jofré y Martínez, "Ruralizando a Dewey", p. 48. 
Tanto Vasconcelos como Mistral habían hecho un camino similar respecto de sus posturas ante la religión, y más exactamente ante el catolicismo: sin dejar de ser cristianos, se habían separado de la Iglesia y se habían abierto espiritualmente hacia las religiones orientales, como el budismo, o corrientes místicas occidentales, como la teosofía. ${ }^{22}$ Ambos leyeron la biografía de Tolstoi, única en su género, escrita por el intelectual francés Romain Rolland, y conocieron profusamente la producción literaria de estos autores. ${ }^{23}$ Otros elementos que unieron a la chilena, al mexicano y a los educadores ruso y bengalí, fueron el pacifismo y el antimilitarismo. Posteriormente, en la década de 1940, la chilena se mantuvo en el cristianismo social, pero el mexicano se inclinó por el nazismo.

Muchos de los cogeneracionales de Vasconcelos, más intelectuales de las generaciones de 1890 , de 1915 y estudiantes de la década de 1920, lo acompañaron en su campaña de "regeneración popular". Uno de estos compañeros (y seguidores, a la vez) fue el joven Jaime Torres Bodet, quien tempranamente -a los 19 años- dirigió la Escuela Nacional Preparatoria y luego fue su secretario particular. En sus Memorias Torres Bodet caracterizó así el ascendiente del

22 En El monismo estético (1918) Vasconcelos ya había adelantado su comprensión para con la cultura india y el budismo, aspectos que consolidó en sus Estudios indostánicos (1920), alabados por Mistral, y fueron una poderosa razón para llegar a México. La poetisa era una profesa teósofa, budista y vegetariana. Véase VAsconcelos, El monismo estético, y TAYLOR, Sensibilidad religiosa de Gabriela Mistral.

23 Moraga, "'Lo mejor de Chile está ahora en México' ”, pp. 1181-1247. Romain Rolland, Vie du Tolstoi. Vasconcelos encargó la traducción de esta biografía a la Universidad Nacional durante su mandato en la SEP, en 1923. Un año después la editorial Claridad, de Buenos Aires, hizo la edición argentina que hemos tenido a mano. 
ministro: "Quien no lo haya tratado en esos días de 1921 no tendrá una idea absolutamente cabal de su magnetismo como 'delegado de la revolución' en el ministerio. La juventud vibró desde luego ante su mensaje, de misionero y de iluminado". ${ }^{24}$ Pero el ministro fue más allá en su admiración por Tolstoi, algo que también reveló su secretario:

Vasconcelos (cuya huella en la educación mexicana será imborrable) profesaba, cuando fundó la Secretaría de Educación Pública, una admiración sin reserva para Tolstoi. Mandó a inscribir su apellido en el friso de su despacho. Y, como él, sacudió con violencia el árbol de la pedagogía burocrática, tan frondoso en manuales sílabos y preceptos. ${ }^{25}$

La fuerte influencia del intelectual ruso en el ministro se produjo porque éste también era cristiano, y entre sus ideas estaba la "educación libre". Vasconcelos lo citó en uno de sus más memorables discursos dirigido a los profesores honorarios, a quienes llamó a redimir al pueblo de "la esclavitud del analfabetismo” enseñándoles la lectura:

Enseñad el secreto de la felicidad, que según Tolstoi consiste en trabajar para la dicha de los otros y no para la nuestra, es decir, para el ideal humano considerado como una anticipación y una senda del ideal divino.

Los profesores honorarios, mejor que ninguna otra clase de ciudadanos, están en condiciones de sentir y propagar esta suprema enseñanza. ${ }^{26}$

24 Torres Bodet, Memorias, vol. I, p. 83.

25 Torres Bodet, León Tolstoi, p. 75.

26 VAsconcelos, "Profesores honorarios". 
La otra fuente ideológica del pensamiento educativo vasconcelista venía de la India. Tanto Vasconcelos como varios miembros de la generación del Centenario, los "ateneístas”, fueron asiduos lectores -entre otros autores- de Tolstoi y de Tagore; aunque solo se ha rescatado la ligazón con la poesía del indio. ${ }^{27}$ En sus Estudios indostánicos (1920) -que lo catapultaron continentalmente-, Vasconcelos dedicó varias páginas a Tagore, a quien clasifica como "ecléctico" y "moderno". ${ }^{28} \mathrm{La}$ admiración de Vasconcelos por el bengalí quedó explícita meses después de salir de la Secretaría, en un texto de su autoría: "El desinterés hace al apóstol, pero el gran apóstol necesita además, del talento y del genio; y en Tagore se juntan las tres categorías supremas: talento, genio y apostolado". ${ }^{29}$ Pero también lo admiraba por su pacifismo. Fell destacó que en El Universal Ilustrado Vasconcelos había declarado: "Las únicas figuras que admiro son las que están desprovistas de sangre y lucro, como Tagore y Gandhi". ${ }^{30}$

Lejos de ser un espacio donde el secretario de Educación impuso sus ideas, el sistema que creó se transformó en un "campo de batalla ideológico" entre distintos proyectos educativos. Esta situación quedó patente en el Congreso de Maestros Misioneros, celebrado en la ciudad de México entre el 18 de septiembre y el 4 de octubre de 1922,

${ }^{27}$ Véase, por ejemplo, el trabajo de TABOADA, “Oriente y el mundo clásico", pp. 103-119.

${ }^{28}$ Fell, José Vasconcelos, pp. 641 y 669, y FeLl, "El ideal literario de José Vasconcelos".

${ }^{29}$ José Vasconcelos, "El apóstol”, La Antorcha (3 ene. 1925), pp. 3-4.

30 El Universal Ilustrado (23 nov. 1923), p. 35, citado en Fell, José Vasconcelos, p. 102. 
organizado por el Departamento de Educación y Cultura Indígena, DECI. En este acto dominaron numéricamente los grupos más radicales de la revolución: socialistas, cooperativistas, agraristas y racionalistas. ${ }^{31}$ Sin embargo, el subsecretario de Educación, Moisés Sáenz, discípulo de John Dewey y seguidor de su "pedagogía activa", parece haber hecho primar sus ideas en los lineamientos que inspiraron la escuela de acción, cuyas Bases se aprobaron en diciembre de 1923. El texto disponía la reorganización de las escuelas primarias, ponía énfasis en la relación profesor-alumno mediante un mejor conocimiento de la fisiología y psicología del niño, así como técnicas de enseñanza que coincidían con los ideales del nuevo régimen que buscaban unir trabajo y estudio, aumentar las actividades manuales y corporales y sustituir el individualismo y la competencia por la cooperación y la solidaridad. ${ }^{32}$ Pero los cambios implementados generaron tensiones entre autoridades, maestros y padres de familia: escuelas no aptas para implementar las labores, maestros con poca preparación, exceso de trabajos manuales y desacuerdos con los padres que rechazaron la coeducación (uno de los fundamentos del sistema), constituyeron los problemas centrales. ${ }^{33}$

31 Un análisis del Congreso en Moraga, “'Lo mejor de Chile está ahora en México””, pp. 1224-1227.

32 Loyo, "La política educativa", p. 23. Después de que Vasconcelos renunció a la SEP, en julio de 1924, hubo un breve interinato de Bernardo Gastellum. Posteriormente José Manuel Puig Casauranc asumió la dirección del organismo, entre 1924 y 1928; lo sucedió el mismo Moisés Sáenz, hasta 1930.

${ }^{33}$ Loyo, "La política educativa", p. 23. Para Bruno-Jofré y Martínez la razón fundamental de los conflictos que generaron las ideas de Dewey, al tratar de implementarlas en México, era el "ahistoricismo" de sus 
Todo indica que, en el debate educativo mexicano, y en general, la "pedagogía de la acción" era un concepto anfibológico que se refería en líneas muy generales a "aprender haciendo" y era aplicado preferentemente a la educación infantil.

Vasconcelos renunció a la Secretaría de Educación Pública en julio de 1924, y en solidaridad lo hizo su colaboradora Gabriela Mistral. El intelectual dejó trunco su proyecto, pero quedó montado un sistema educativo que en los años siguientes sufriría modificaciones, reformas políticas e ideológicas, pese a las cuales se mantuvo un cierto sustrato cultural que sería parte de un intenso debate en los años siguientes y que retornaría con el tiempo.

\section{NUEVOS PROYECTOS DE EDUCACIÓN: \\ NACIONALISMO VS. SOCIALISMO}

Con la llegada de Plutarco Elías Calles al poder en 1924 el gobierno modificó la política educativa de acuerdo con el nuevo régimen económico de orientación nacionalista. Éste, al contrario del vasconcelista, era un sui géneris nacionalismo proestadounidense; ello significó que la influencia de Tolstoi y Tagore en la ideología pedagógica oficial disminuyera y aumentara considerablemente la educación basada en los planteamientos de Dewey. Hay que advertir que ésta no era una tendencia que se produjera solo en México.

planteamientos. Éstos subestimaban "las condiciones estructurales de la sociedad y las fuerzas políticas, sociales y culturales", lo que chocaba con la extrema socialización que sus seguidores mexicanos intentaban implementar en el sistema educativo. Bruno-Jofré y Martínez, "Ruralizando a Dewey”, p. 45. 
La influencia que alcanzó la pedagogía del estadounidense en varios países del mundo occidental fue impresionante; incluso, a pesar de las distancias geográficas, Dewey penetró en la Rusia zarista desde mediados de la década de 1910 y, pese a las distancias ideológicas y políticas, se mantuvo incluso en la Rusia soviética hasta casi $1928 .{ }^{34}$

El cambio en la supremacía de las ideas pedagógicas hizo que se multiplicaran las escuelas rurales: el objetivo era formar trabajadores más productivos, moralizar mediante una "religión cívica” y "desfanatizar" a la población campesina e indígena, en su mayoría católica, por medio de campañas de salud e higiene y la promoción de la enseñanza técnica. En general, los objetivos de la nueva política eran más pragmáticos que los del pasado gobierno y estaban plagados de un fuerte anticlericalismo. A la cabeza de ese proceso se puso el propio Moisés Sáenz, el anterior subsecretario. ${ }^{35}$

Dependencias como las Casas del Pueblo cambiaron de nombre pero siguieron con su labor de modificar hábitos domésticos y técnicas agrícolas, así como combatir supersticiones y prácticas retardatarias, por medio de la promoción de campañas de higiene y salud, deportivas y artísticas. También se multiplicaron las Misiones Culturales y se creó una dirección para regularlas, pero su labor se interrumpió por la guerra cristera (1926-1929). El proyecto estrella del callismo fue el de las Escuelas Centrales Agrícolas, destinadas a formar agricultores prósperos y modernos a semejanza de los farmers estadounidenses. Entre 1926 y 1933 se establecieron seis costosas Escuelas Centrales dependientes de

\footnotetext{
34 Véase Mchitarjan, “John Dewey”, pp. 163-186.

35 Loyo, "La política educativa”, p. 23.
} 
la Secretaría de Agricultura y Fomento. Este año pasaron a depender de la SEP y se fusionaron con las Normales Rurales y las Misiones, formando la Escuela Regional Campesina: el objetivo era hacerlas más eficientes y mejor adecuadas a las necesidades del mundo rural; tenía como misión formar expertos agrícolas y maestros rurales. ${ }^{36}$

En 1925 se dio vida a un viejo anhelo que venía desde 1867, cuando se fundó la Escuela Nacional Preparatoria: se creó la escuela secundaria, que siguiera a la primaria y fuera alternativa y no antesala obligatoria a la profesionalización. Con ello no solo se daba una salida a quienes no podían realizar estudios universitarios, además perseguía que los jóvenes no se involucraran en la política contingente y se distrajeran de los estudios; sin embargo, ello profundizó el conflicto con la Universidad, que se vio privada de su preparatoria. Otra de las innovaciones implementadas fue el Departamento de Enseñanza Técnica, Industrial y Comercial, que coordinó las escuelas vocacionales y técnicas en rápido crecimiento.

Pero el organismo más controvertido de la administración Calles fue el Departamento de Psicología e Higiene. El secretario de Educación Pública, el médico José Manuel Puig Cassauranc, junto con otros educadores e higienistas, lo creó para impulsar la salud física y psíquica de la población y la "pureza” de la "raza”. Además se reemplazó el DECI por el Departamento de Escuelas Rurales e Incorporación Indígena, donde Moisés Sáenz intentó homogeneizar el caleidoscopio cultural mexicano y crear una sola civilización. Investigaciones recientes han catalogado estos y otros

${ }^{36}$ Loyo, "La política educativa”, p. 25. 
organismos del callismo, inspirados en el higienismo y la eugenesia, como parte de un proyecto racista impulsado desde el Estado mexicano en un momento de ascenso del nazismo en el mundo. ${ }^{37}$

El proceso de organización del sistema educativo en la segunda mitad de la década de 1920 estuvo marcado por el excesivo sesgo ideológico del gobierno, lo que llevó a un conflicto con otro de los grandes poderes educacionales en México: la Iglesia católica. Durante el primer lustro Vasconcelos había demostrado suficiente flexibilidad al aplicar el artículo 3ํ de la Constitución de 1917 y no le importó el signo religioso mientras se expandiera el sistema educativo y se fundaran escuelas. Pero el nuevo grupo en el poder hizo gala de un dogmatismo laicista y anticatólico que fue enfrentado con la formación de la Liga de la Defensa Religiosa. ${ }^{38} \mathrm{El}$ gobierno emitió un reglamento provisional de escuelas primarias particulares del D. F. y territorios, que intentó atenuar con la publicación de un Código de moralidad, para las escuelas oficiales que ratificaba los valores de la educación laica. La Iglesia protestó suspendiendo el culto público y conminó a los padres a no enviar a sus hijos a la escuela; el gobierno contestó prohibiendo el culto privado y persiguió las ceremonias clandestinas. El conflicto redundó en el abandono de las escuelas oficiales. ${ }^{39}$

1929 fue el año del fin de la guerra cristera y del establecimiento de lo que se ha llamado un modus vivendi entre el Estado y la Iglesia católica; también se declaró la autonomía de la Universidad Nacional, lo que zanjó el largo conflicto

37 URías Horcasitas, Historias secretas.

38 Loyo, Gobiernos revolucionarios, p. 250.

39 Loyo, Gobiernos revolucionarios, p. 252. 
entre la SEP, el gobierno y la Universidad, que había llegado a su punto máximo de tensión. Ese mismo año el asesinato del presidente electo Álvaro Obregón produjo un vacío de poder que llenó Calles manejándolo por medio del novel Partido Nacional Revolucionario (PNR).

El fin de este complejo frente de conflictos posibilitó al gobierno iniciar una serie de modificaciones. Ello se tradujo en grandes campañas sanitarias contra el alcoholismo y en la elaboración de textos que le permitieran tener mayor contacto con el mundo rural y campesino y transmitir su mensaje nacionalista. Así nacieron la revista mural El Sembrador y Fermin. ${ }^{40}$ Pero El Maestro Rural fue la publicación más rutilante; dirigida por el joven intelectual Salvador Novo, en sus páginas aparecieron ilustraciones de grabadores y muralistas como Diego Rivera y José Clemente Orozco. Quienes la han trabajado aclaran que "era en realidad una revista hecha por intelectuales para intelectuales", que se propuso comunicar la cúpula de la SEP con los maestros rurales y la base campesina que paulatinamente se habían incorporado al mundo lector. ${ }^{41}$

En el plano ideológico, pese al rampante "pragmatismo" y a que, oficialmente, Dewey había desplazado a Tolstoi y Tagore, éstos siguieron presentes en el debate pedagógico mexicano. El ingeniero agrónomo Gonzalo Robles, "otro personaje que desempeñó un papel central en los planes de Calles”, visitó Estados Unidos, donde observó las escuelas de agricultura; en Europa visitó "cooperativas, escuelas

\footnotetext{
${ }^{40}$ Loyo, "Lectura para el pueblo", pp. 289-345.

${ }^{41}$ Loyo, "La política educativa”, p. 31. Sobre El Maestro Rural, véase el completo y sugerente libro de Palacios, La pluma y el arado.
} 
agrícolas, bancos cooperativos e industrias agrícolas"; lo mismo hizo en América del Sur. Pero también fue a la URss, donde se entrevistó con Lunacharski y visitó escuelas, "especialmente la de Tolstoi: Yasnaia Poliana". ${ }^{42}$

Durante el sexenio de Lázaro Cárdenas (1934-1940) se implementó uno de los proyectos educativos más controvertidos del siglo xx: la "educación socialista”. Pero éste no fue impulsado solo "desde arriba" por el Estado federal. En su génesis participaron organizaciones estudiantiles, obreras y magisteriales en un proceso de "radicalización de la cultura escolar", que pugnaron por darle a los programas educacionales mayor contenido social. Esto fue acompañado de la crisis económica de México en 1926 y del sistema capitalista mundial en 1929, que llevó a muchos a pensar que era la crisis terminal del sistema capitalista anunciada por Marx en $E l$ manifiesto comunista en 1848 y que ahora, por inercia histórica, sobrevendría inevitablemente el socialismo.

A la cabeza de la "educación socialista" se colocó otro intelectual, Narciso Bassols, perteneciente a la generación de los "siete sabios", quien se caracterizó por su radicalismo y su anticlericalismo. Se dio un nuevo impulso a las Misiones Culturales para "desfanatizar" a la población, lo que fue resistido en especial por las clases medias y la Iglesia, con un proyecto que insistió en la modernización del campo, tanto en el plano productivo como en el social y cultural. ${ }^{43}$

En 1933, durante la Segunda Convención Ordinaria del PNR, se aprobó el plan sexenal, que reforzó el papel

42 Meneses Morales, Tendencias educativas ... 1911-1934, p. 454.

${ }^{43}$ Narciso Bassols, "Clausura de la Asamblea de Directores de Educación, de Directores de Escuelas Normales Rurales y de Jefes de Misión”, en Bassols, Obras, p. 118. 
conductor del Estado en varios aspectos de la vida social y se pronunció a favor de la educación socialista, popular y extensiva que privilegiara la enseñanza técnica por sobre las profesiones liberales. ${ }^{44}$ La reforma al artículo $3^{\circ}$ de la Constitución declaraba a la educación que impartiría el Estado como "socialista", que excluiría toda doctrina religiosa y que combatiría el fanatismo y los prejuicios. ${ }^{45}$

Después del amplio cuestionamiento y oposición sobrevino una nueva etapa que coincidió con el desarrollo de la segunda guerra mundial. El gobierno de Manuel Ávila Camacho (1940-1946) impulsó un cambio en el modelo económico que privilegió la industrialización y el desarro1lo, por lo que la educación fue el elemento fundamental para dar impulso a la economía. Sin embargo, el gobierno se comportó errático en la superación de los conflictos sociales, políticos e ideológicos, lo que se reflejó en la designación de tres secretarios de Educación con orientaciones diferentes. Primero nombró a Luis Sánchez Pontón (19401941), partidario de la educación socialista; luego a Octavio Véjar Vázquez (1941-1943), políticamente conservador, quien entró decidido a eliminar toda influencia izquierdista

${ }^{44}$ Lombardo Toledano, La doctrina socialista. Sobre el movimiento de autonomía en la UNAM véase MARsiske, "Antecedentes del movimiento estudiantil de 1929”, pp. 141-176, y Contreras Pérez, “La autonomía universitaria de junio de 1929 a septiembre de 1935", pp. 333-443.

${ }^{45}$ Existe gran cantidad de monografías sobre la educación socialista, en especial algunas destinadas a los estados. Sin embargo, no existe una obra general que permita hacerse una idea acabada sobre el conjunto del proceso. Algunos trabajos significativos son: Loyo, "La difusión del marxismo y la educación socialista"; Civera Cerecedo, Entre surcos y letras; Kelly, A Chapter in Mexican Church-State Relations; y Navarro García, Revolución en rojo. 
en la educación. Aunque definió un nuevo orden educativo, la "escuela del amor", terminó expulsando a los maestros de izquierda, en especial a los rurales, y devolvió influencia a la Iglesia católica en el campo. ${ }^{46}$

El secretario impulsó un cambio en el artículo $3^{\circ}$, el que, sin embargo, no fue modificado en su redacción (la educación socialista siguió "vigente") sino en su sentido: ahora el "espíritu" de la ley era totalmente distinto. El "socialismo" era aquel que había forjado la revolución mexicana: "Una doctrina de solidaridad y respeto a la colectividad cuyo propósito era disminuir las desigualdades económicas y sociales", con el fin de convertir a la escuela en un espacio de unidad de los mexicanos. En suma: se suprimió la educación mixta, el campo dejó de ser el foco de atención y el objetivo se reorientó hacia lo urbano y la industrialización, y se privilegió un sentido nacionalista y conservador: "Formar buenos ciudadanos, conscientes de sus derechos y obligaciones, respetuosos de la ley y leales a México, fue la consigna que sustituyó a la lucha de clases". ${ }^{47}$

\section{EL PROYECTO EDUCATIVO DE VASCONCELOS}

Después de su salida de la SEP, Vasconcelos inició un largo y controvertido exilio en que su figura como intelectual se acrecentó internacionalmente en la misma medida que disminuían sus capacidades para incidir en la política concreta de su país. Entre 1924 y 1928 viajó por Estados Unidos y varios países de Europa, donde tuvo contacto con

\footnotetext{
${ }^{46}$ Greaves, "En busca de la modernidad", p. 37 y La alternativa moderna. 47 Greaves, "En busca de la modernidad", p. 38.
} 
intelectuales como el francés Romain Rolland; en 1927 participó en el Congreso Antiimperialista de Bruselas, donde fue el representante oficial de los países latinoamericanos y, como tal, le tocó dar el discurso oficial a nombre de la delegación. ${ }^{48}$ Pero el "vasconcelismo", como movimiento de intelectuales interesados en la política, siguió existiendo y dio una gran batalla en 1929, cuando el líder se presentó a las elecciones presidenciales contra el candidato oficial del callismo, Pascual Ortiz Rubio.

En el contexto de un nuevo exilio político, el exministro se permitió fijar sus ideas educativas en De Robinson a Odiseo. Pedagogía estructurativa, que publicó en Madrid en 1935. Vasconcelos explicó el sentido de esta obra, poco apreciada por sus biógrafos: "Sin vocación alguna pedagógica, sin práctica del magisterio, publico este libro únicamente para explicar cómo procedió un filósofo cuando el destino le llevó a la tarea de educar un pueblo". ${ }^{49}$

Pero, más allá de sus intenciones explícitas, su objetivo era combatir las diferentes ideas pedagógicas que se habían implementado después de su salida de la Secretaría. Pese

${ }^{48}$ El Primer Congreso Mundial contra el Imperialismo y la Opresión Colonial se celebró en Bruselas en febrero de 1927. Fue un escenario de enfrentamientos entre las propuestas antiimperialistas encabezadas por Haya de la Torre y las que sostenía la Liga Antiimperialista de las Américas, LADLA, de orientación comunista, representada por el cubano Julio Antonio Mella (que mantenía una extraña alianza con el presidente de México, Plutarco Elías Calles, enemigo político de Vasconcelos). No fue esto lo único sui géneris en el acto, en sus Memorias, Vasconcelos se reconoció entonces como socialista y hombre de izquierda. Melgar, Vivir el exilio, pp. 25-28.

49 Vasconcelos, De Robinson a Odiseo. Para el presente trabajo hemos tentido a mano la edición, basada en el original madrileño, de 2002. 
a que las orientaciones que le imprimieron Moisés Sáenz, durante el maximato, y la educación socialista durante el cardenismo -en el poder en ese momento-, eran diferentes, la influencia de la pedagogía de Dewey parece haber sido común a todas.

Pero el secretario dio un giro insospechado, en su obra no solo combatió a Dewey: De Robinson a Odiseo tiene una profunda inspiración antirousseauniana, que Vasconcelos expresó contra la idea del filósofo belga de la "pureza virginal del niño”. Esta oposición lo llevó incluso a distanciarse de su más grande inspirador:

El niño inocente y el criminal irresponsable, la sociedad verdugo; ni cristianos sinceros, como Tolstoi, escapan a la tesis vagamente generosa pero inexacta. El creyente que hubo en Tolstoi se hubiese sorprendido si descubre que, al glosar en su literatura las doctrinas naturalistas de su época, se ponía en contradicción con la tesis cristiana del pecado original. ${ }^{50}$

Este rechazo y cambio de simpatía intelectual es extraña, dada la profunda religiosidad cristiana que unió al mexicano con el ruso, pero para Vasconcelos esto incluso era anticientífico. Sin embargo, si se alejó de Tolstoi, ¿quién era el eje central de su "pedagogía estructurativa"? Esto lo aclara en las conclusiones del libro:

En educación, como en cualquier otra actividad, es preciso tomar en cuenta la índole de la época en que se vive, y no es ésta la del establecimiento del hombre en el planeta, sino, muy al contrario, la primera ocasión en que la vida humana se funda en

${ }^{50}$ Vasconcelos, De Robinson a Odiseo, p. 12. 
experiencias milenarias tan remotas como las de los vedas y los egipcios. Tan viejo y reconstruido es el ambiente, querámoslo o no, que ni el mismo se sustrae a él ni intenta sustraerse. ${ }^{51}$

Vasconcelos reeditó esta obra en 1952, en México, por Editorial Constanza. Pero esta vez introdujo un cambio importante, ya que, además del subtítulo original, fue incluido otro en la portada: "Pragmatismo o clasicismo en la escuela hispanoamericana”. Esto lo hizo con el claro propósito de remarcar la raíz cultural de su proyecto y diferenciarlo de la influencia estadounidense en la educación que predominaba en ese momento.

Páginas atrás señalábamos que el "hispanismo constructivo y coherente" de Vasconcelos, la doctrina filosófica e ideológica que profesó durante gran parte de su vida y que elaboró conforme escribía y actuaba en la política, proviene del uruguayo José Enrique Rodó y su libro Ariel, publicado en 1900. La idea básica de este ensayo es que existe una contradicción cultural histórica entre la América del Norte (Estados Unidos) y la América del Sur: la una era anglosajona y la otra, latina; mientras la primera se caracterizaba por su cultura pragmática, la segunda lo hacía por su idealismo; una producía en el campo material, la otra en el espiritual. Rodó era liberal, y había tomado del filósofo católico francés Ernest Renan esta idea -conocida ya en el continente sudamericano desde la década de 1860-, que la publicitó hasta que fue tomada como de su creación original. ${ }^{52} \mathrm{El}$

51 Vasconcelos, De Robinson a Odiseo, pp. 257-258.

52 Al igual que Vasconcelos, Renan tuvo etapas en su vida en que se alejó del catolicismo y otras en que volvió a su culto. Sobre el arielismo en general véase Carlos Real de Azúa, “Prólogo a Ariel”, en Rodó, Ariel, 
arielismo era "latinizante", es decir, era una doctrina fundada políticamente en el liberalismo y culturalmente en el legado de la Ilustración y la ciencia de raíz francesa. Vasconcelos era culturalmente conservador, era católico y sus fundamentos estaban ligados a España, no a Francia. Por lo tanto su arielismo lo podemos denominar "hispanista" o "hispanizante". ${ }^{53}$

Desde las independencias de las excolonias españolas y durante gran parte del siglo XIx, la cultura liberal se fundó en el romanticismo, constituido en la herencia cultural y política de la revolución francesa y la Ilustración, mientras que la cultura conservadora se cimentó en la herencia colonial hispana clásica, basada en la religión católica y el idioma español, lo que conformaba lo que se denominó en la época "clasicismo", fundado en el pensamiento escolástico promovido por el imperio español y rescatado por los conservadores. En líneas muy generales, estos referentes organizaron y dividieron el cuadro político e ideológico continental; así se opuso liberalismo y conservadurismo, romanticismo y clasicismo, agnosticismo y catolicismo, progreso y statu quo, ciencia y fe. Solo a fines del siglo xIx, cuando Estados Unidos arrebató al imperio español las islas de Cuba y Puerto

p. x, y Devés, Del Ariel a la Cepal. Véase Moraga Valle, "Guerra, liberalismo y utopía”, pp. 419-450.

${ }^{53}$ En la carta a Romain Rolland, ya citada, Vasconcelos definió así su actitud hacia el legado cultural francés: "A pesar de todo, nosotros resistimos las influencias del momento y seguimos creyendo en una latinidad de savia española y de alcance universal que acoja en su seno a todas las razas para la libertad y el bien. Y si en esta empresa no nos desentendemos del todo de Francia es justamente porque Francia sigue contando con espíritus como el de usted, que ponen ejemplo de universalismo fecundo". VAsconcelos, "Carta a Romain Rolland", en Obras completas, t. II, p. 854. 
Rico, sus últimas posesiones coloniales, España perdió para el mundo liberal el carácter conservador y fue objeto de interés de los intelectuales liberales del continente. ${ }^{54}$

Pero en la década de 1920 no había un solo "ismo" para denominar a la América que existía al sur de Estados Unidos. Desde fines del siglo xix y por las razones expuestas más arriba, la denominación "Hispanoamérica" había ganado adeptos ante el "Panamericanismo", promovidos por el país del norte. Pero muchos intelectuales, de enorme peso e influencia, no parecen haber tenido ninguna preferencia especial. El peruano José Carlos Mariátegui usaba indistintamente "Iberoamérica", "Indoamérica” y América Latina"; mientras que el chileno Joaquín Edwards Bello usaba "América indo-mediterránea" y "América indo-íbera". ${ }^{55}$

La América de Vasconcelos no es geográficamente tan “amplia” como la Pan América promovida por Estados Unidos, ni la Latinoamérica impulsada por Renan y popularizada por Rodó. El mexicano apunta más bien a una realidad cultural establecida; al fin y al cabo esta parte del nuevo continente había sido colonizada por España desde el siglo xvi y los liberales latinoamericanos no podían despegarse del incómodo hecho de que Francia había fracasado en el intento de tomar para sí la hegemonía política y cultural, con la invasión a México, durante la segunda mitad del siglo XIx..$^{56}$

Pero Vasconcelos no estaba solo en este orden de ideas, junto a él había una pequeña pero significativa generación de

\footnotetext{
${ }^{54}$ Sobre el hispanoamericanismo como proyecto cultural véase GrANADos, Debates sobre España.

55 Moraga Valle, “¿Una nación íbero, latino o indoamericana?”, pp. 247-279.

${ }^{56}$ Vasconcelos, Memorias, El desastre, p. 793.
} 
intelectuales latinoamericanos. Ideas similares fueron sostenidas por los chilenos Gabriela Mistral y Joaquín Edwards Bello, los peruanos Santos Chocano y Víctor Raúl Haya de la Torre, y el argentino Leopoldo Lugones. ${ }^{57}$

Por lo anterior, en la reedición de 1952 de De Robinson a Odiseo, Vasconcelos retomó el concepto decimonónico de "clasicismo", para oponerla al pragmatismo callista y al socialismo cardenista, ambos plagados de ateísmo. ${ }^{58}$

\section{EL REGRESO DEL PROYECTO VASCONCELISTA A LA SEP}

El viraje conservador impuesto en la SEP por Octavio Véjar solo agudizó las diferencias entre distintos sectores del gremio magisterial y amenazó con el retorno de la inestabilidad. Por ello Ávila Camacho llamó a Jaime Torres Bodet a la dirección, donde, entre 1943 y 1946, “desarrolló una importante labor como moderado y conciliador ideólogo de la educación”. Torres Bodet era entonces el personero más

${ }^{57}$ La mayoría de estos intelectuales girarían su pensamiento hacia la derecha a fines de la década de 1930 y en la de 1940. Solo Mistral se mantuvo en posiciones democráticas. Vasconcelos fue propagandista del nazismo; Joaquín Edwards Bello fue partidario de un "nacionalismo continental", una especie de fascismo hispanoamericano, y Haya de la Torre imprimió un sello nacionalista y antiizquierdista al Partido Aprista Peruano, heredero de la Alianza Popular Revolucionaria Americana, APRA. Moraga VALLE, “¿Una nación íbero, latino o indoamericana?”, pp. 247-279.

${ }^{58}$ Deber tenerse en cuenta que este "retorno" de Vasconcelos a sus raíces culturales conservadoras lo hizo después de su controvertida "etapa nazi”, en que publicó la revista Timón, donde hizo propaganda a los países del eje contra los aliados liderados, en la etapa final de la segunda guerra mundial, por Estados Unidos (su viejo enemigo). Al menos en este aspecto, Vasconcelos era coherente con su fobia a todo lo que significara asumir el legado cultural del Calibán estadounidense. 
que idóneo para el puesto: amplio conocedor de la institución desde sus inicios, había sido primero secretario en la Escuela Nacional Preparatoria y luego secretario particular de Vasconcelos; además, era diplomático de carrera. Durante su mandato se realizó el Primer Congreso de Educación Nacional y se retomaron aspectos centrales del proyecto vasconcelista de educación: se volvió a realizar una campaña contra el analfabetismo y se inició la publicación de la Biblioteca Enciclopédica Popular. ${ }^{59}$ Además, coordinó la nueva redacción del artículo tercero constitucional aprobado por el Congreso en el año de 1944, con lo que se superó un conflicto de varios años; el texto, que mantuvo sin cambios la parte conceptual, definía y precisaba la naturaleza, objetivos y fines de la educación mexicana. ${ }^{60}$

Durante el mandato del presidente Miguel Alemán Valdés (1946-1952), y después de su exitosa gestión en la SEP, Torres Bodet fue nombrado secretario de Relaciones Exteriores (1946-1948). Continuó su carrera diplomática desde ese año hasta 1952, como secretario de la Organización de las Naciones Unidas para la Educación, la Ciencia y la Cultura, unEsCo. Eran años difíciles por la guerra fría, además de las enormes diferencias entre los países industrializados y aquellos que no lo estaban. ${ }^{61}$ Pero sobre todo fueron

59 Esta biblioteca estaba compuesta por "modestos libros semanales" de los que se editaron 134 números. "Está pensada para poner en contacto a los lectores con obras inalcanzables desde México y se distribuyó gratuitamente entre los maestros rurales." Según Woldenberg “Se trata de expandir un hábito al que se supone fundamental para el enriquecimiento de la existencia". Woldenberg, "Torres Bodet: carácter y trayectoria", p. 89.

60 Torres Septién, Pensamiento educativo, p. 10.

${ }^{61}$ Torres Bodet en Torres Septién, Pensamiento educativo, p. 11. 
los años en que se consolidó el proceso de descolonización de la India. De alguna manera se cumplía el sueño de Tagore, quien había muerto en 1941, pero quedaba en el escenario una de las figuras indias cercanas a Tolstoi en la ideología pacifista que había encabezado el proceso independentista: Mahatma Gandhi. A Torres Bodet le tocó ser un testigo privilegiado de estos acontecimientos y protagonizó la inclusión de la India en el nuevo sistema de relaciones internacionales mediante la educación.

Un discurso suyo revela la permanencia en su pensamiento educativo de Rabindranath Tagore, a quien citaba textualmente: "No hay más que un camino que conduzca a los objetivos universales que la UNESCO persigue: el esfuerzo aunado de todas las culturas, aportando cada una de ellas, no la uniformidad incolora, sino la plenitud de su rica diversidad, con la comprensión mutua para cimentar el todo". ${ }^{62}$

En la unesco Torres Bodet continuó en la senda que ya había caminado: solucionar los problemas de la educación básica, extender la educación primaria, la educación de la mujer y la educación para el civismo; a la vez que implementó el intercambio de estudiantes y maestros y la circulación de material educativo de todo tipo. En 1951, por encargo de ese organismo fundó en Michoacán el Centro Regional para la Educación, que tenía como misión preparar especialistas en el área. ${ }^{63}$ Pero también desarrolló una profunda cercanía con la India y sus gobernantes, en especial con Jawaharlal Nehru, y con su hija, Indira Gandhi, a quienes conoció en

${ }^{62}$ El Correo, publicación de la Organización de las Naciones Unidas para la Educación, la Ciencia y la Cultura, II: 4 (mayo 1949).

${ }_{63}$ Torres Septién, Pensamiento educativo, p. 11. 
1951 y que recibiría, diez años más tarde, en México como secretario de Educación, en una visita que recordó, conmovido, en sus memorias. ${ }^{64}$

Torres Bodet ganó experiencia y estatura en su cargo internacional y con ello trató de dar un nuevo impulso al sistema educativo, pero en México los conflictos del gremio educativo se transformaron en un problema endémico. ${ }^{65}$ Para 1958, cuando inició el sexenio de Adolfo López Mateos (1958-1964), el sistema diseñado por Vasconcelos había sido sobrepasado por el aumento de la población y la incapacidad propia: ya no cubría la demanda educativa, ni las necesidades del Estado mexicano en torno de la industrialización y el desarrollo económico. El conflicto de 1958 fue una gran lección para el Ejecutivo. La política económica conocida como "desarrollo estabilizador", que se había iniciado durante el sexenio anterior (de Ruiz Cortines, 1952-1958), era un intento de estabilizar la economía que implicaba un enorme esfuerzo organizador de la educación, para disponer de mano de obra capacitada. Ello requería nombrar a una persona con capacidad, experiencia y que garantizara una relativa estabilidad en las relaciones con el sindicato. Por segunda vez un presidente de la República

64 Torres Bodet, Memorias, pp. 450-452.

65 Delgado de Cantú, Historia de México, p. 356. Junto con Torres Bodet, una extensa generación de latinoamericanos desembarcó en la dirección de los distintos organismos internacionales. El mexicano Víctor L. Urquidi participó en la Conferencia de Chapultepec, que inició la formación de la onU; el chileno Felipe Herrera Laine dirigió el Banco Interamericano de Desarrollo, BID, y el peruano David Tejada de Rivera, la Organización de las Naciones Unidas para la Alimentación y la Agricultura, FAO. 
recurrió al exdiscípulo de Vasconcelos. ${ }^{66}$ Cuando éste reasumió la dirección de la SEP no solo era el mexicano, sino el latinoamericano, con más autoridad y experiencia en el ramo de la educación en el ámbito mundial, con una trayectoria y una concepción pedagógica forjadas en distintas áreas de la dirección de planes de educación a lo largo de 44 años.

Durante ese segundo mandato se articuló y echó a andar por primera vez un proyecto de educación técnica nacional que consistía en aumentar la cobertura e incluir con ello a la población excluida; pero además, implicaba ampliar el sistema a la educación técnica. Con ello se buscaba cumplir con los acuerdos de la Conferencia de Educación de Santiago de Chile. Esto significaba que México debía aumentar el financiamiento a la educación, que a inicios de la década de 1960 era de $2.4 \%$ del producto nacional bruto. ${ }^{67}$

El regreso de Torres Bodet significó también el regreso del proyecto vasconcelista a la SEP. Tanto el conocido Plan de los Once Años, como el impulso a la distribución del libro de texto gratuito, demuestran una inconfundible raíz tanto en lo implementado entre 1922 y 1924, como en la edición y distribución de los "libros verdes" ${ }^{68}$ Esta continuidad de las ideas de Tagore en el pensamiento educativo

\footnotetext{
66 Torres Bodet, Memorias.

${ }^{67}$ Pese a que el "Plan de once años" utilizó métodos estadísticos avanzados para la época, no se tenía certeza del número total de niños en edad escolar; sin embargo, se sabe cuánto aumentó la cobertura, que pasó de 30816 escuelas en 1958 a 37576 en 1964 (un incremento de 21\%), y cuánto la matrícula nacional de 4105302 a 6605757 (un incremento de 60.9\%). Torres Bodet, Memorias, pp. 376-385.

${ }^{68}$ Barriga Villanueva (ed.), Entre paradojas.
} 
del secretario también implicó al otro ideólogo que hemos analizado. En 1964, cuando terminó su segundo periodo al mando de la SEP, Torres Bodet volvió a sus temas de juventud y publicó una biografía de León Tolstoi, la única escrita directamente en español. ${ }^{69}$ En su Tolstoi, el exsecretario reflexionó sobre los móviles más íntimos de su concepción educativa. La obra, escrita en el formato tradicional, se centra en el autor de Ana Karenina; sin embargo, la experiencia de vida le ganó al biógrafo y dedicó páginas fundamentales a reflejar su concepción y su experiencia sobre la educación. De hecho, el tema sale en la narración y escapa abruptamente al objetivo biográfico del libro. Todo se produce en una parte clave, cuando el ruso regresó a su natal Yásnaia Poliana, cansado ya de una agitada vida de juveniles excesos sensuales y lúdicos, con el propósito de sentar cabeza. Allí era señor feudal de una gran propiedad rural y de mucha servidumbre; entonces se topó con una serie de "rústicos y locuaces" niños:

De su maestro Rousseau -dice Torres Bodet- había heredado, junto con el amor de la naturaleza, una intención pedagógica muy marcada. Seguía siendo el Emilio uno de sus libros fundamentales. Además de Rousseau, había leído a Pestalozzi y a Froebel. Juan Jacobo patrocinó la doctrina: no hay programa que valga para todos los niños en general. La educación constituye un proceso personalísimo". ${ }^{70}$

69 Torres Bodet, León Tolstoi.

70 Torres Bodet, León Tolstoi, pp. 73-74. Torres Bodet había leído Emilio alrededor de 1920, cuando pasaba de la Escuela Nacional Preparatoria a ser secretario particular de Vasconcelos. En la revista El Maestro comentó el libro de Rousseau con una perspectiva crítica, que no aceptaba el utopismo educativo de Rousseau: "Y es que no se forma un hombre 
En su Tolstoi el intelectual secretario juntó en su análisis a los principales teóricos sobre la educación de la Ilustración y el romanticismo; en particular le interesaron los aspectos sobre instrucción que valoraban la intuición como motor de la educación, especialmente popular e infantil. Aunque el biógrafo nos advierte que la tesis básica provenía de Montaigne, la concepción de pedagogía (popular) del ruso le resulta "sugestiva, aunque -en sus últimas consecuencias- terriblemente antidemocrática". En su análisis Torres Bodet funde sus propias reflexiones en torno de la educación con las de Tolstoi; lo propuesto por Rousseau (y Pestalozzi y Froebel) no se podía aplicar (¿a Rusia de mediados del siglo xIX o a México de mediados del Xx?) a una nación con 2000000 de niños los que, para educarlos, requerían de 2000000 de profesores, por lo tanto: "Se imponía el aula, el grupo escolar. Y la ley del guía, frente al grupo que está a su cargo, ha de ser ante todo el respecto de la personalidad infantil, para afirmarla y perfeccionarla. Gracias a la intuición, según Pestalozzi, el alumno podía avanzar de lo más sencillo a lo más complejo". ${ }^{71}$

como se escribe un libro; es que un espíritu no surge de una tesis, por excelente que sea, y es también que abstraer al niño de la influencia materna, intentar colocarlo en mitad de la naturaleza multánime, sin que una ternura lo ampare y un corazón lo guíe, es proponer utopías y ambicionar imposibles", Torres Bodet, "El Emilio de Rousseau".

71 Torres Bodet, León Tolstoi, p. 74. Torres Bodet había sostenido coherentemente con su planteamiento de 1965, en 1921, en un breve artículo en El Maestro, que: "el verdadero error de Rousseau no estuvo en exigir al educador ciertas virtudes difíciles, sino en creer que era imprescindible encontrar un ayo para cada discípulo. Considerando, como es menester, que hacer de cada padre un pedagogo es casi un imposible, se convierte la doctrina de Rousseau en una doctrina aristocrática, formulada para 
De la reflexión de estos filósofos de la educación se desprendía que en la "educación acción" "no es posible separar la acción del conocimiento y que conocimiento y acción deben llevarse a cabo en una escuela eminentemente práctica: la vida". Ello llevó a Torres Bodet a valorar el kindergarten que cultivaba al niño en las "condiciones que la naturaleza aconseja". La pedagogía "vitalista" de Tolstoi -como la definió nuestro autor- se nutrió de estos autores aunque en más de una oportunidad su espíritu rebelde lo llevó a tildar al kínder de "creación monstruosa" y a las teorías de estos intelectuales como erigidas "sobre la nada". Para el ruso la dirección correcta no iba de lo simple a lo complejo, sino todo lo contrario: la vida empezaba exponiendo lo complejo y el maestro era quien debía reducir eso a elementos simples para el estudiante, donde el sujeto central del proceso educativo era el niño. ${ }^{72}$

Torres Bodet no solo analiza panorámicamente las concepciones pedagógicas desde Montaigne hasta Tolstoi, sino que también nos entrega valiosa información sobre el proyecto educativo que Vasconcelos elaboró durante los años previos a asumir la dirección de la educación nacional y que estuvo presente en el sistema educativo desde 1921 hasta, al menos, la década de 1960. El ministro filósofo en su concepción de educación -compartida por Torres Bodet, tanto, que no dudó en examinarla en medio de la biografía que le dedicara a uno de los inspiradores- llamaba a: “ ¡No perder la esperanza! He allí la ley esencial de todo

vástagos de familias acaudaladas y elegantes”. Torres BodET, “El Emilio”, p. 36.

72 Torres Bodet, León Tolstoi, p. 74. 
magisterio genuino. En 1921 Vasconcelos no la olvidaba. Por eso -como Tolstoi- tenía una fe tan robusta en los niños del mundo entero" ${ }^{73}$

\section{LA RECEPCIÓN DE TAGORE \\ EN EL PROYECTO VASCONCELISTA}

Pero, ¿se puede hablar de continuidad del proyecto vasconcelista de educación en 1960 cuando desde el mismo día que abandonó la Secretaría sus sucesores aplicaron otras teorías educativas? Hemos sostenido que una de las fuentes ideológicas del proyecto vasconcelista de educación proviene de Rabindranath Tagore. Pero no fue el poeta y educador bengalí quien abrió el camino a la recepción de la cultura india en Occidente sino un intelectual anterior, el swami (maestro) Vivekananda, quien en 1893 viajó a Chicago, al Congreso Mundial de las religiones. Las ideas de este religioso indio tuvieron mucha aceptación en Estados Unidos, por lo que se quedó un par de años dando conferencias en distintos espacios donde propagó la filosofía vedānta y la práctica del yoga ${ }^{74}$ Su biografía, escrita por Romain Rolland, fue traducida al español y publicada en Buenos Aires a mediados del siglo xx. ${ }^{75}$

Los supuestos que alentaban la obra educativa de Vasconcelos en la SEP y la del poeta y educador indio son muy similares. Éste creía, al igual que el mexicano, que la construcción de la nación (y su independencia) se lograrían

\footnotetext{
73 Torres Bodet, León Tolstoi, p. 76.

74 Preciado, "Las relaciones entre México y la India”, pp. 891-892. Martínez Ruiz, "Being, thinking and educating.

75 Rolland, Vida de Vivekananda.
} 
educando a la mayoría de la población, que permanecía inculta; preceptos que llevó a cabo en su escuela en Santiniketan (Bengala Occidental). ${ }^{76}$

Este intelectual indio bengalí nació en Calcuta el 7 de mayo de 1861; fue poeta y filósofo del movimiento Brahmo Samaj (después convertido al hinduismo), además de artista, dramaturgo, músico, novelista y compositor. Extendió el amplio arte bengalí con poemas, historias cortas, cartas, ensayos y pinturas, y también fue un sabio y reformador cultural. Perteneció a una familia profundamente religiosa: su padre, Debendranath Tagore, formuló la fe Brahmo propagada por el amigo de su abuelo, el rajá reformador Rammohun Roy. Niño (era el menor de 14 hijos), vivió en el ambiente del "renacimiento indio", caracterizado por la publicación de revistas literarias y de representaciones musicales y de teatro; en Bengala en particular éste también tuvo tres vertientes: religiosa, cultural y nacional. ${ }^{77}$ En 1878 viajó a Brighton, Inglaterra, para estudiar en una escuela pública y continuó en el University College de Londres, sin embargo, solo estuvo allí un año. La exposición a la cultura y lengua inglesas se manifestaron en sus diferencias con la tradición musical bengalí, que lo llevó a crear nuevas formas de

76 TAgore, La luna nueva. Alfonso Reyes, “ateneísta” de gran ascendiente sobre su generación y las posteriores, poseía una extensa biblioteca sobre ambos autores (tal vez la más rica de sus congéneres), donde hay 40 obras del autor indio y 25 del ruso. Véase Olguín García y SAUCEDo, Capilla Alfonsina. De la misma manera Antonio Caso, filósofo y profesor universitario, compañero de ambos, hizo una profunda y radical lectura de La guerra y la paz, y en general de toda la obra de Tolstoi, que definió, en gran parte, su vida académica y su reflexión filosófica plasmada en su obra más importante; véase CASO, La existencia como economía. 77 Vinod Jalan, “Tagore: His Educational Theory”, pp. 1 y 2. 
música. Pero Tagore fue un profundo ecléctico: nunca abrazó completamente las rígidas normas inglesas, ni la estricta interpretación de la religión hindú tradicional de su familia en su vida o en su arte; en su lugar tomó lo mejor de ambas esferas de experiencia. ${ }^{78}$

Hacia 1883 se había convertido en el centro de atención del mundo literario con varias obras. En 1890 se marchó a gestionar las propiedades familiares en Shelaidaha (Bangladés). Los trabajos de este periodo (Sonar Tari, 1894; Chitra, 1892, y Katha O Kabini, 1900) lo consagraron como poeta, además de ensayista, escritor de obras y de historias cortas que reflejaban la vida del pueblo. ${ }^{79}$ En 1901 dejó Shelaidaha y se trasladó a Shantiniketan (Bengala Occidental), donde fundó una escuela experimental, en la propiedad que heredó de su padre. Esta escuela, establecida según la tradicional estructura brabmacharya de los estudiantes viviendo junto a su gurú en una comunidad autosuficiente, atrajo a grupos internacionales de estudiantes, artistas, lingüistas y músicos.

Tagore continuó escribiendo obras, como Naivedya (1901) y Kheya (1906). ${ }^{80}$ Por ese entonces, ya tenía un amplio número de seguidores entre los lectores bengalíes. También se llevaron a cabo algunas traducciones de sus obras, pero como muchas en la época, de calidad dudosa. En esos años de comienzos de siglo Tagore tradujo algunos de sus poemas en verso libre que, en 1912, llevó a Inglaterra, donde causaron

\footnotetext{
78 Thompson, Rabindranath Tagore: His Life and Work.

79 Thompson, Rabindranath Tagore: Poet and Dramatist.

${ }^{80}$ El 9 de diciembre de 1883, Rabindranath se casó con Mrinalini Devi; tuvieron cinco hijos pero varios murieron en sus primeros años. Hacia 1906 también murió su mujer, una de sus hijas más queridas y un hijo, lo que lo dejó destrozado. Thompson, Rabindranath Tagore, p. 56.
} 
una honda conmoción al poeta angloirlandés W. B. Yeats y al misionero inglés Charles F. Andrews (protegido de Gandhi). El Gitanjali, en su versión inglesa, fue publicado por la Sociedad India con un notable prólogo de Yeats, lo que a Tagore le significó ganar el premio Nobel de Literatura, en noviembre de 1913. Fue el primer laureado no europeo en obtener este reconocimiento. Junto con Charles F. Andrews y W.W. Pearson, se embarcó en 1916 en un circuito de conferencias por Japón y Estados Unidos y sus traducciones se multiplicaron. Tagore denunció el chovinismo nacionalista y los nacionalismos beligerantes de todo el mundo, incluyendo el japonés y el estadounidense, y escribió el ensayo Nacionalismo en la India, donde abordó el tema de su tierra natal. Esta posición le hizo recibir muchas críticas, aunque también elogios, como los del pacifista Romain Rolland.

Hacia 1918, de regreso a Shantiniketan, se desempeñó como asistente y mentor, en lo que pasó los siguientes años; daba clases en las mañanas y elaboraba personalmente los libros de texto de los alumnos durante las tardes. Dedicó prodigiosas cantidades de energía a obtener fondos para esta escuela, y no dudó en utilizar lo ganado con el Nobel. Hoy la institución es conocida como Universidad Visva Bharati ("India en el mundo").

Durante un viaje frustrado al Perú, pasó el verano de 1924 en Buenos Aires, Argentina, donde trabó una profunda relación con la escritora Victoria Ocampo, quien lo llevó a vivir a su casa. En 1925, viajó a Italia, Suiza, Austria, Checoslovaquia, Hungría, Rumanía, Yugoslavia, Bulgaria y Grecia. Pasó a Egipto, luego a Rusia y Canadá, antes de volver a Inglaterra. Dos años después, junto con dos compañeros, recorrió durante cuatro meses Bali, Java, Kuala Lumpur, 
Malaca, Penang, Siam y Singapur. Los diarios de este viaje fueron recopilados en su obra Jatri.

Tagore escribió varias canciones apoyando el movimiento independentista indio. Tras la masacre de Jallianwala Bagh (Amritsar) en 1919, rechazó el título de caballero que le había concedido la corona británica en $1915 .{ }^{81}$ Tagore desarrolló esta idea de que la nación y su independencia se logran mediante la educación en su escuela de Santiniketan. Mantuvo, además, múltiples contactos con otros intelectuales de su tiempo, lo que lo convirtió en un puente entre la India y occidente y un "traductor" del milenario legado cultural de su nación al mundo. ${ }^{82}$

Pero, ¿ cómo podemos sostener que las ideas pedagógicas que ensayó un escritor y educador indio, basadas en milenarias tradiciones de un extenso y lejano país, llegaron a México a inicios de la década de 1920? Y más aún, ¿cómo permanecieron en el debate educativo hasta, al menos, la década de 1960? Hemos visto fehacientemente cómo las ideas de Tolstoi respecto de la educación influyeron en Vasconcelos, incluso polémicamente, en De Robinson a Odiseo. Pero Tagore aparece más como escritor que como pedagogo, no solo en Vasconcelos, sino también en toda su generación y en su colaboradora Gabriela Mistral. He aquí alguna de las actitudes

${ }^{81}$ Brown, "In Book Reviews; South Asia”. Swinson, Six Minutes to Sunset.

${ }^{82}$ Entre sus contactos estaban Henri Bergson, Albert Einstein, Robert Frost, Mahatma Gandhi, Thomas Mann, George Bernard Shaw, Victoria Ocampo, H. G. Wells, Romain Rolland, Juan Ramón Jiménez y Zenobia Camprubí. Ésta tradujo a Tagore del inglés en 1915, con La luna nueva y El jardinero; además de su teatro, poesía y prosa. Fue una verdadera recreación, que tuvo enorme eco en los escritores de lengua española de todo el mundo. 
con que la chilena llegaba a las misiones culturales y las campañas de alfabetización impulsadas por Vasconcelos:

Iba a los pueblos. Adoraba a la gente de campo y en seguida se entendía con ella. Hablaba con los maestros, los veía trabajar; hacía para ellos pláticas y conferencias sobre el sentido de la enseñanza, sobre los fines que perseguían en las nuevas escuelas, sobre el material escolar, sobre la enseñanza de la Geografía y de la Historia, sobre los libros para los niños y para los jóvenes, sobre el uso de las bibliotecas, sobre la cultura necesaria al maestro y a la mujer $[\ldots]{ }^{83}$

Aun así, y aunque los misioneros mexicanos dieran clases al aire libre o en el campo, ¿ es factible que el sistema brabmacharya de los estudiantes viviendo junto a su gurú en una comunidad autosuficiente inspirara las misiones culturales? Este aspecto es polémico sobre todo si explícitamente Vasconcelos sostuvo que la idea de las misiones provenía de los misioneros católicos de la colonia. Y aun así, ¿quién o quiénes trajeron esas ideas y cómo llegaron al bagaje cultural de un filósofo y político mexicano? En este aspecto hay que recurrir a otro intelectual que estableció un puente entre la lejana Europa Central y Asia, con el mundo occidental europeo y latinoamericano, y ese fue el escritor francés Romain Rolland.

Rolland sucedió a Tagore en la obtención del premio Nobel, en 1915 (no se otorgó el año anterior por el estallido de la guerra). Había nacido el 29 de enero de 1866 en Clamecy, Nièvre. Su primer libro fue publicado en 1902. Trece años más tarde ganó el premio Nobel de Literatura "como tributo al elevado idealismo de su producción

83 Guillén, “Gabriela Mistral (1922-1924)”, p. ix. 
literaria y a la simpatía y el amor por la verdad con el cual ha descrito diversos tipos de seres humanos". Su existencia, marcada por su pasión por la música y el heroísmo, hizo que durante toda su vida buscara medios de comunión entre los hombres. Su imperiosa necesidad de justicia le llevó a buscar la paz durante y después de la primera guerra mundial. Fue un gran admirador de León Tolstoi, de los filósofos de la India; quedó fascinado por el intelectual persa Bahá'u'lláh; recibió el influjo de la filosofía hinduista del Vedānta, tema al que dedicó varios libros. ${ }^{84}$ Después

${ }^{84}$ La filosofía vedānta (del sánscrito veda: "conocimiento, sabiduría” y anta: "final, conclusión”) es una escuela dentro del hinduismo. Esta denominación se interpreta en un doble sentido: como "la culminación de la sabiduría”, en sentido absoluto, como el conocimiento espiritual más elevado; y como "la última parte de los vedas", en sentido cronológico, pues esta doctrina completó el reemplazo de la religión védica (expresada en el texto épico mitológico Rig-veda) por la nueva religión hinduista. A la doctrina vedanta también se la conoce como úttara mimamsa ("superador del mimamsa"), para contraponerla con la antigua doctrina mimamsa (“interrogantes”), que se ocupaba de las explicaciones para los sacrificios de fuego de los mantras védicos (que se encuentran en la parte Samjita del Rig-veda) y de los textos brahmanas. El texto principal de la doctrina vedanta es el Vedanta-sutra de Badaraiana, de 200 a. C. Según la tradición posterior, Badaraiana es un nombre de Viasa, uno de los sabios más o menos legendarios a quienes se atribuye el Rig-veda, compuesto mil años antes. El texto está formado por cientos de frases lacónicas y relativamente sin conexión entre sí. Por su parte, el hinduismo no es una religión, en el sentido occidental del concepto, sino un credo -según Mahatma Gandhi- "inclusivo y omniabarcante”, de modo que "cualquier cosa esencial, contenida en cualquier religión, se encontrará siempre en el hinduismo". Para este ideólogo se le puede definir como "buscar la verdad por medios no violentos" y creer en los textos sagrados escritos por "inspiración divina": los vedas, los Upanishads y los Puranas. GANDHI, Gandhi, sobre el hinduismo, pp. 15-16. 
de la guerra admiró el nuevo mundo que preconizaba la Unión Soviética. ${ }^{85}$

Aceptado en la École Normale Supérieure en 1886, primero estudió filosofía, pero la abandonó para no someterse a la ideología dominante. Se graduó en Historia en 1889 y pasó dos años en Roma, donde su encuentro con Malwida von Meysenbug -quien había sido amiga de Nietzsche y de Wagner-y su descubrimiento de las obras maestras italianas fueron decisivos en el desarrollo de su pensamiento. Cuando regresó a Francia en 1895, se doctoró con la tesis "Los orígenes del teatro lírico moderno. Historia de la ópera en Europa antes de Lully y Scarlatti”.

Primero ejerció como profesor de historia en liceos y más tarde enseñó historia de la música en la Sorbona e historia en la École Normale Supérieure. Exigente, tímido y joven, no le gustaba enseñar, aunque no fue indiferente a la juventud (los personajes de sus novelas son jóvenes), pero tanto con éstos como con los adultos sólo mantuvo relaciones distantes. Seguro de que podría vivir dedicado a la literatura, renunció a la universidad en 1912; tres años después ganó el premio Nobel de Literatura y en 1922 fundó la revista Europe.

Fue un pacifista militante. En 1924, su biografía de Gandhi contribuyó a la posterior reputación de éste, pero se conocieron solo en 1931. Se trasladó a las playas del Lac Léman, Suiza, para dedicarse a escribir. En 1935 viajó invitado por Máximo Gorki a Moscú, donde conoció a Stalin, y sirvió extraoficialmente como embajador de los artistas franceses

${ }^{85}$ Esta influencia quedó patente en sus obras Conversaciones con Rabindranath Tagore y Mohandas Gandhi; en Clerambault, novela en la que expone sus ideas sobre la guerra, hace referencia a Baháu'lláh, y en Tolstoi (1911), la biografía del escritor y educador ruso. 
en la Unión Soviética. En 1937 regresó a vivir a Vézelay, que tres años después fue ocupada por los alemanes, tiempo durante el cual se aisló en completa soledad. En 1940 terminó sus Memorias y concluyó su investigación musical sobre la vida de Ludwig van Beethoven. Poco antes de su muerte, escribió Péguy (1944), en la que examina la religión y el socialismo en el contexto de sus memorias. En 1921, su amigo, el escritor austríaco Stefan Zweig, escribió su biografía: Romain Rolland. El hombre y su obra; Zweig admiraba profundamente a Rolland, de quien una vez, durante la guerra, aseveró que era "la conciencia moral de Europa". ${ }^{86}$

Su obra maestra, Juan Cristóbal, consta de diez volúmenes en los que describe la vida de un genial músico alemán, muestra el universalismo y el amor a la humanidad. Es autor de las biografías de Beethoven, Miguel Ángel, Tolstoi, Gandhi, San Luis y Péguy. ${ }^{87}$ Sus Carnets, comenzados en 1906, son su diario íntimo, de gran valor autobiográfico. Su vida y su obra fueron una constante aspiración hacia la paz; en ellas trató de expresar una concepción de la vida y de los valores individuales superiores dentro de la realidad histórica, de la convivencia social y del pacifismo y el internacionalismo; por ello fue desterrado a Suiza.

Si Tagore y Tolstoi habían traducido una parte del mundo oriental para Occidente, Rolland cumplió el mismo papel para América Latina, además de ser un atento seguidor de lo que sucedía en el México posrevolucionario. ${ }^{88}$ Desde su

${ }^{86}$ Zweig, Romain Rolland, p. 67.

87 Las biografías de los tres primeros fueron publicadas en 1923, en un volumen titulado Vidas ejemplares, cuya traducción fue encargada por Vasconcelos a la SEP.

${ }^{88}$ Rolland no solo presentó a Tolstoi en América Latina, sino también a 
exilio en Suiza, siguió cuanto hizo Vasconcelos en la Secretaría y no dudó en señalarlo como un líder continental, vinculándolo a la escuela fundada por Tagore. ${ }^{89}$ Gabriela Mistral, junto con su secretaria y amiga mexicana Palma Guillén (otra colaboradora del ministro), lo visitaron en su residencia del lago Leman y se sorprendieron gratamente: “Le oímos asombradas lo que va contando del movimiento social mexicano y su conocimiento perfecto de la reforma educacional de Vasconcelos. No le interrumpimos, ni afianzamos su elogio del amigo, con el nuestro, por gozar, palabra a palabra, del juicio”. El francés también les habló de la "cuestión agraria” y de las "leyes sociales del presidente Obregón”; incluso les confesó que después de publicar su Gandhi, estaba planeando una biografía del intelectual mexicano. ${ }^{90}$

Tagore y a místicos indios en las biografías Vida de Ramakrishna. Ensayo sobre la mística y la acción de la India viva, Buenos Aires, Librería Hachette, 1953 y Editorial Kier, 1976, y Vida de Vivekananda.

89 En una carta a Rolland le expresaba: "Espero que algún día conozcan en Santiniketan a José de Vasconcelos (el exministro de Instrucción Pública de México) y su obra admirable de educación pública. Él encabeza a toda la joven América”. Rolland, "Carta a Kalinas Nag”, 9 de febrero de 1925. Era una respuesta a la lealtad intelectual que había demostrado el ministro en una misiva, en respuesta a otra del galo, fechada el 9 de enero de 1924. Vasconcelos confesó -alrededor de 1916-, desde su destierro empujado por el carrancismo: "he seguido sus escritos como se sigue a un guía o a un maestro". Pero en sus Memorias el filósofo ateneísta confesó que, con el tiempo, el "sovietismo integral... el ateísmo cientifizante y la irreligiosidad” lo habían separado del maestro francés. José Vasconcelos, "Carta a Romain Rolland", México, 1922, en Vasconcelos, Obras completas, t. II, p. 855; Memorias, El desastre, vol. II, p. 504.

${ }^{90}$ SCARPa, Gabriela piensa en..., pp. 294-295. 
LA RECEPCIÓN DE LAS PROPUESTAS EDUCATIVAS. TOLSTOI EN MÉXICO

Pero, en definitiva, ¿qué llevó a Vasconcelos, Alfonso Reyes, Gabriela Mistral y al mismo Torres Bodet y a toda una generación de intelectuales, no solo mexicanos, sino también latinoamericanos, a valorar lo escrito por un intelectual ruso muerto cuando recién iniciaba la revolución mexicana? Y no solo a valorarlo, sino también a aplicarlo en un sistema educativo que fundamentara los cimientos de la nación.

Tolstoi era un intelectual que creció en un país "periférico" al mundo europeo occidental, cuando reinaba el "paradigma del progreso". Este "paradigma", sostenido por el avance del capitalismo industrial a fines del siglo xIx y basado ideológicamente en un discurso liberal positivista, dio sustento al dominio político de la oligarquía durante la etapa 1870 a 1914 y se detuvo con el estallido de la primera guerra mundial. Nada de eso ocurría en el entorno social y político en el que creció y se desarrolló, y ello llevó al autor de Ana Karenina a rechazar, al principio, tanto la sociedad del progreso como su educación.

Para Torres Bodet, el desdén de Tolstoi por los adultos se mezclaba con la ironía hacia los intelectuales sometidos a "la mística del progreso". Ante esto oponía un acatamiento a "las leyes de la naturaleza", es decir, vivir en armonía con la tierra y el cielo de su país; esto lo llevaba a dudar de la efectividad de la educación para la felicidad humana para los pobres y humildes: nuevos conocimientos suscitarían nuevas necesidades que no podrían después satisfacer. Por lo tanto había que acompañar la obtención de la educación (para ello se basaba en Rabelais y en Bergson) con un 
"robustecimiento de la seguridad interior de quien conquista la información". Por lo anterior, Tolstoi preconizaba más la "instrucción” y la difusión de la cultura, a la que oponía la “educación”. Mientras la primera era posible la segunda no. Los maestros podían instruir, en cambio, la educación solo era posible cuando el individuo se educaba a sí mismo. Pero, con el correr de los años, maduró sus concepciones y llegó a fundir una con otra: "Educación en instrucción son indivisibles", sentenció el ruso. ${ }^{91}$

De regreso en Yásnaia Poliana, en 1861, Tolstoi puso en práctica todo lo aprendido en sus viajes por Europa, especialmente por Alemania y Bruselas; en ésta conoció, entre otros, al anarquista Pierre-Joseph Proudhon. ${ }^{92}$ Por ello quiso poner en práctica la libertad como regla esencial de la escuela que había fundado en 1849, donde la disciplina era resultado de la voluntad colectiva de todos los estudiantes y no una imposición de los maestros. Ello porque en su concepción la "verdadera instrucción" debía ser espontánea, y el centro debía estar en el desarrollo en los estudiantes de las virtudes del campesino ruso: "su sencillez y su repugnancia para todo lo que contiene alguna falsía”. Todo esto lo volcó en una revista, Yásnaia Poliana, publicada desde febrero de 1862, que no le produjo seguidores inmediatos, pero sí las antipatías del gobierno que, por medio del ministro de Instrucción Pública, criticó las propuestas pedagógicas del escritor por ser "contrarias a las reglas fundamentales de la religión y de

\footnotetext{
91 Torres Bodet, León Tolstoi, p. 77.

92 De hecho, Torres Bodet señala que las conversaciones con Proudhon fueron las que inspiraron el título de La guerra y la paz, la novela máxima de Tolstoi, que empezó a escribir alrededor de 1873. Torres Bodet, León Tolstoi, p. 77.
} 
la moral". La situación llegó a un extremo cuando la escuela fue allanada y la policía registró incluso sus papeles personales. Sin embargo, la aldea de Yasnaia Poliana se convirtió en un "lugar de peregrinación" de artistas e intelectuales del mundo "no occidental"; a la escuela llegaban no solo escritores rusos, sino también indios y africanos; paradójicamente, ese nutrido intercambio cultural transformó a Tolstoi en un verdadero traductor del mundo oriental para occidente. ${ }^{93}$ Pero, ¿ cómo fue tomada la obra de un reconocido autor anarquista por los bolcheviques, sus tradicionales rivales y hasta enemigos políticos, transformados por Lunacharski en un proyecto y un sistema educativos? Lo concreto es que, prácticamente desde el mismo día de su muerte, el propio Lenin escribió para un periódico parisino un obituario del escritor en el que reinterpretaba el significado de su obra desde el punto de vista de la revolución burguesa campesina (de 1905), pero criticó su pacifismo. ${ }^{94}$

¿En qué aspectos se diferenciaba el proyecto educativo de Tolstoi, que asumieron tanto Vasconcelos como Torres Bodet, y que llevó a éste a escribir -admirado- una biografía del ruso? En poco, es más, había coincidencias importantes, tanto en la tradición intelectual clásica de la "generación del Centenario" y la de sus sucesores, "los sabios", y la de otro aspecto oculto de la práctica pedagógica que Tolstoi aplicó a sus propios hijos y que era opuesta a la que usó en su escuela destinada a los niños campesinos hijos de sus propios

\footnotetext{
93 Shifman, Tolstoi and India, pp. 3-5.

94 Vladimir Ilich Lenin, "León Tolstoi", en El Socialdemócrata, 16 (29) de noviembre de 1910, en Lenin, Obras, t. XVI, pp. 293-297. SÁncheZ VÁzQUEZ, "Ideología política y literatura”, pp. 216-230.
} 
siervos. ${ }^{95}$ Esto porque, por sus lecturas del Emilio, el autor ruso aplicaba los rígidos valores pedagógicos de la clásica Esparta junto con los libertarios de Atenas, que trataba en su libro el filósofo ginebrino. ${ }^{96}$ Sin embargo, Tolstoi manifestaba una fuerte contradicción cuando aplicaba su concepción de educación: mientras con los campesinos aplicaba preceptos espontaneístas e intuicionistas de educación, a sus hijos les enseñaba según el método tradicional de enseñanza de las humanidades, que consistía en el aprendizaje de lenguas vivas y muertas, en agotadoras jornadas de estudio y lectura. ${ }^{97}$

Romain Rolland, activo pacifista fue gran admirador del pacifismo de Tolstoi, Tagore y Gandhi, de las enseñanzas de Ramakrishna y Vivekananda; quedó fascinado por Bahá'u'lláh (a quien hace referencia en Clerambault, novela en la que expone sus ideas sobre la guerra) y posteriormente por el nuevo mundo que la Unión Soviética preconizaba en sus comienzos; recibió el fuerte influjo de la filosofía vedānta. De hecho su biografía de Tolstoi, publicada en 1911 en francés, fue profusamente leída en América Latina, en especial entre la intelectualidad antioligárquica. ${ }^{98}$

95 Torres Bodet, León Tolstoi, pp. 98-99. Tanto un trabajo ya clásico sobre Vasconcelos, como es el de Claude Fell, como uno más reciente acerca la "generación del Centenario", de Susana Quintanilla, han destacado la admiración de Vasconcelos y sus compañeros hacia la cultura clásica. Véanse Fell, José Vasconcelos, y Quintanilla, “Dioniso en México”, pp. 619-663.

96 En Emilio, o sobre la educación, Rousseau recurre, en las pocas notas que contiene esta obra, fundamentalmente a autores clásicos (Platón, Plutarco, Pitágoras, Virgilio) y a algunos contemporáneos (Buffon, Chardin, Pascal, etc.), además de a algunos pasajes de la Biblia. Jean Jacques RousSEAU, Emilio.

97 Torres Bodet, Tolstoi, p. 98.

98 Rolland, Vida de Tolstoi. 
Tolstoi no se conformó con fundar una escuela para los hijos de los campesinos; se hizo su profesor, escribió y editó los libros de texto con que estudiaban. Impartía módulos de gimnasia y prefería el jardín para dar clases. Creó para ello una pedagogía libertaria cuyos principios instruían en el respeto a ellos mismos y a sus semejantes..$^{99}$ Pero, ¿̇cuál es la conexión entre ambos escritores tan geográficamente lejanos a México y América Latina? Alexander Shifman en su Tolstoi and India, se adentra en la relación entre ambos autores analizando la visita del ruso a la India. Este texto es clave para entender algo que nuestros estudios advirtieron tempranamente: la fuerte conexión entre el proyecto educativo del intelectual ruso y la patria de Tagore: éste -nos lo señala Shifman- "considered Tolstoi 'as the theacher of mankind' and urged people to listen to his voice". ${ }^{100}$ Lo anterior pese a que, al parecer, ambos no se conocieron personalmente.

Además Tolstoi tenía otra fuerte ligazón con la India: su amistad epistolar con Mahatma Gandhi. Este intercambio produjo la escritura de El reino de Dios está en vosotros, que solo fuera publicado en Alemania en 1894, ya que fue censurado por el zar, lo que no impidió que el texto circulara clandestinamente por varios países de Europa. Esta cercanía era tanta que uno de los últimos actos vitales del escritor ruso, pocas semanas antes de morir en la estación de ferrocarril de Astapovo, fue escribirle al indio una extensa carta en que le clarificaba sus doctrinas pacifistas. ${ }^{101}$

\footnotetext{
99 Tolstor, La escuela de Yasnaia Poliana.

100 Shifman, Tolstoi and India, p. 42.

101 El título de este polémico libro fue tomado de una cita del evangelio de Lucas 17:21, del Nuevo Testamento. Basado en las enseñanzas de Jesús, Tolstoi habla aquí del principio de no resistencia en oposición a la
} 
En resumen, hacia inicios del siglo xx y hasta su muerte, Tolstoi no solo era un escritor de prestigio, también era un reformador educacional, en la teoría, y también en la práctica; inspirado en una doctrina anarquista, producto de su contacto con Proudhon, y pacifista, con grandes nexos culturales e ideológicos con la India y con intelectuales como Tagore y el joven Gandhi, con quienes compartió una doctrina basada en el culto a la tierra y a las tradiciones campesinas y agrícolas. Pero también era un profundo cristiano alejado de las ortodoxias de las jerarquías religiosas. Además, tenía una fuerte formación política que lo había llevado a colocarse como uno de los primeros antiimperialistas, producto de su experiencia política y de ser testigo del avance del imperialismo colonialista de los países occidentales sobre el oriente indio y chino, tanto que se había vuelto molesto para el propio emperador ruso. Todo ese bagaje cultural fue tomado por Romain Rolland, un intelectual de prestigio en Occidente y que adquiriría una fuerte influencia una vez concluida la guerra mundial, cuando se jugarían todos estos componentes como alternativa a la guerra, la colonización y al avance del industrialismo. Es resumen, Tolstoi fue uno de los ideólogos más ecléctico, potente y novedoso de la época, cuya influencia se extendió entre

violencia. Lo que intentaba Tolstoi era separar el cristianismo ortodoxo ruso (según él, demasiado involucrado en el Estado) de lo que él creía el verdadero mensaje de Jesucristo, el mensaje que figura en los evangelios, y en especial del Sermón de la Montaña. Solo recién se ha publicado en ruso y traducido al español. Estuvo censurado por la Iglesia cristiana ortodoxa durante muchos años y en Italia y España por la Iglesia católica, pero circuló clandestinamente por el resto de Europa. Tolstor, El reino de Dios está en vosotros. 
los anarquistas rusos que se opusieron al autoritarismo bolchevique, entre los anticolonialistas indios, como Gandhi (cuyos efectos se verían solo finalizada la segunda guerra mundial), sobre los pacifistas franceses como Rolland, y sobre Vasconcelos y Mistral y la formación del sistema educacional mexicano, que se prolongó hasta 1964 con Torres Bodet, el sucesor del proyecto vasconcelista de educación.

\section{CONCLUSIONES}

La construcción de la nación es un proceso nunca acabado o, tal como lo dijera el inspirador de Rodó, Ernest Renan en 1882: "un plebiscito permanente". Ello se corrobora cuando analizamos el proceso de formación y consolidación del sistema educativo mexicano en la etapa que nos ha ocupado. La historia de la educación en México entre 1921 y 1964 ha sido como la larga construcción de un rascacielos diseñado por arquitectos discípulos de escuelas disímiles. Los planos y las bases fueron discutidos desde fines del porfiriato y diseñados en el transcurso del proceso revolucionario, pero su construcción se inició en 1921.

En la anterior resultaron claves dos generaciones de intelectuales: la de 1910 o "del Centenario", más conocida como la del Ateneo de la Juventud, y la de 1915, que posteriormente se llamó de los "Siete Sabios". Los ateneístas abrieron el debate sobre la construcción de la nación porque consideraban que México había alcanzado su "mayoría de edad" y estaba a punto de pasar a su "etapa adulta”, pero sobrevino la Revolución. Como lo señalara Alfonso Reyes, uno de los hombres más insignes de la generación de 1910, en Pasado inmediato, durante el porfiriato: "el advenir hace un alto"; 
desatada la Revolución que "brotó de un impulso, más que de una idea", tuvo que pasar la etapa armada para que se fuera esclareciendo sola conforme andaba; y conforme andaba, iba descubriendo sus razones cada vez más profundas y extensas y definiendo sus metas cada vez más precisas".

El proceso que vivió el sistema educativo mexicano pasó por varias de estas etapas de búsqueda y debate, pero también de confrontación y lucha. La mayoría de los trabajos sobre el periodo destacan la influencia ideológica y teórica de la revolución rusa y de su ministro de educación, Anatoli Lunacharski, en el diseño del proyecto vasconcelista de educación; otros, la pedagogía de John Dewey. Si bien no dejan de tener razón, han obviado la clara influencia y aun permanencia de los dos intelectuales de la educación y el pacifismo más importantes de fines del siglo XIX e inicios del xx: León Tolstoi y Rabindranath Tagore. Su influencia y la permanencia en el pensamiento de Vasconcelos, primero, y de Torres Bodet después, es clave para explicar la formación de un sistema educativo nacional y el fortalecimiento de la nación mexicana a lo largo de cuatro décadas de desarrollo de la Secretaría de Educación Pública.

Hasta cierto punto es normal que la herencia de Tolstoi y de Tagore en el proyecto educativo de José Vasconcelos haya pasado desapercibida por tanto tiempo para los estudiosos de la historia de la educación en México. La revolución rusa, que tuvo un fuerte impacto en las izquierdas latinoamericanas, y en general en todo el debate político desde fines de la década de 1910, en México fue menos influyente, naturalmente, por la fuerza del proceso revolucionario local y las urgencias del momento. Hay, entonces, un primer tamiz impuesto a la influencia del bolchevismo 
en el debate político e ideológico posrevolucionario. Por otra parte, el mismo proyecto revolucionario soviético, y la labor propagandista de su ministro de educación, no demostró mayor interés por clarificar el origen de las ideas de Lunacharski. Una revolución anticapitalista por definición está contra la nobleza y, por añadidura, contra esa "nobleza populista” rusa de fines del siglo XIX que coqueteaba con el anarquismo. Después del zarismo, el segundo enemigo interno a vencer para los discípulos de Lenin, fueron los anarquistas, a los que reprimió en Kronstadt, en 1921. Por ello, es natural que el régimen bolchevique recién instalado no estuviera muy interesado en propagar el origen tolstoiano del proyecto educativo revolucionario, máxime cuando la ideología tolstoiana era pacifista, algo que no se condecía con el entusiasmo revolucionario que había hecho de la lucha armada un leitmotiv contra el zarismo en Rusia, y en México contra el "antiguo régimen” porfirista.

Si el proceso ruso soviético tuvo menos importancia aparente, el proceso indio lo tuvo menos aún. Faltaban años y una segunda guerra mundial para que la colonia inglesa que era la India, sometida al "protectorado" cuyos corifeos eran los rajás locales, se liberara por medio de una revolución pacifista. Pese a que las novelas de Tagore eran conocidas por la élite de la intelectualidad latinoamericana desde principios de siglo, solo una minoría de ésta conocía las ideas y el proyecto pedagógico del bengalí.

Pero más allá de esto, ambos "intelectuales periféricos" influyeron en el proceso posrevolucionario mexicano, no sólo en Vasconcelos y Torres Bodet, por medio de las grandes campañas de alfabetización, la distribución gratuita de libros y las Misiones Culturales, sino también en una 
importante fracción de los educadores mexicanos, quienes interrumpida pero tenazmente implementaron sus ideas en diversas dependencias de la SEP, y en general en el sistema educativo mexicano durante gran parte del siglo xx.

\section{SIGLAS Y REFERENCIAS}

ASEP Archivo de la Secretaría de Educación Pública, México. AHUNAM Archivo Histórico de la Universidad Nacional Autónoma de México.

Barriga Villanueva, Rebeca (ed.)

Entre paradojas: A 50 años del libro de texto gratuito, México, El Colegio de México, Secretaría de Educación Pública, Comisión Nacional de Libros de Texto Gratuitos, 2012.

Bassols, Narciso

Obras, México, Fondo de Cultura Económica, 1964.

Brown, Emily

"In Book Reviews; South Asia", en The Journal of Asian Studies, 32:3 (mayo 1973), pp. 522-523.

Bruno-Jofré, Rosa y Carlos Martínez Valle

"Ruralizando a Dewey: el amigo americano, la colonización interna y la escuela de la acción en el México posrevolucionario (1921-1940)", en Encuentros sobre Educación, 10 (otoño 2009), pp. 43-64.

Caso, Antonio

La existencia como economía, como desinterés y como caridad, en Antonio Caso, Obras Completas, vol. III, México, Universidad Nacional Autónoma de México, 1972.

Civera Cerecedo, Alicia

Entre surcos y letras: educación para campesinos en los años treinta, Zinacantepec, México, El Colegio Mexiquense, 
Instituto Nacional de Estudios Históricos sobre la Revolución Mexicana, 1997.

Contreras Pérez, Gabriela

"La autonomía universitaria de junio de 1929 a septiembre de 1935, en Historia general de la Universidad Nacional, siglo XX. De los antecedentes a la Ley Orgánica de 1945, México, Universidad Nacional Autónoma de México, 2010, pp. 333-443.

Delgado de Cantú, Gloria M.

Historia de México, formación del Estado moderno, México, Alambra Bachiller, 1987.

Devés, Eduardo

Del Ariel a la Cepal, Buenos Aires, Biblos, 1999.

Fell, Claude

José Vasconcelos. Los años del Águila, 1920-1925, México, Universidad Nacional Autónoma de México, 1989.

“El ideal literario de José Vasconcelos (1916-1930)", en Nueva Revista de Filología Hispánica, XLII: 2 (1994), pp. 549-562.

Fernández Mac Gregor, G.

Vasconcelos, México, Secretaría de Educación Pública, 1942.

GANDHI, Mahatma

Gandhi, sobre el hinduismo, Madrid, Ediciones Siruela, 2006.

Garza Elizondo, Humberto y Susana Chacón (coords.)

Entre la globalización y la dependencia. La política exterior de México, 1994-2000, México, El Colegio de México, Tecnológico de Monterrey-CCM, 2002.

Gazarian, Marie-Lise

"Gabriela Mistral como educadora", en Revista Hispánica Moderna, 34:3/4, II (jul.-oct. 1968), pp. 647-660. 
Gonzalbo, Pilar y Anne Staples (coords.)

Historia de la educación en la Ciudad de México, México, El Colegio de México, 2012.

Granados, Aimer

Debates sobre España. El hispanoamericanismo en México a fines del siglo XIX, México, El Colegio de México, 2010.

Greaves, Cecilia

“En busca de la modernidad (1940-1970)", en SEP noventa años, 1921-2011. Cimientos de la nación, México, Instituto Nacional de Antropología e Historia, 2011.

La alternativa moderna: política educativa del gobierno federal, 1940-1964, México, C. Greaves Laine, 2005.

Guillén, Palma

“Gabriela Mistral (1922-1924)”, en Gabriela Mistral, Lecturas para mujeres, México, Secretaría de Educación Pública, 1978.

Guzmán, Eulalia

La escuela nueva o de la acción, México, Cultura, 1924.

Kelly, María Ann

A Chapter in Mexican Church-State Relations: Socialist Education, 1934-1940, Mich., University Microfilms International, 1975.

LENIN, Vladimir Ilich

"León Tolstoi", en El Socialdemócrata, 16 (29) de noviembre de 1910, en Lenin, Obras, t. XVI, pp. 293-297.

"Leo Tolstoy as the Mirror of the Russian Revolution", en Proletary, 35, 11 septiembre (24), 1908 en Lenin Collected Works, vol. 15, Moscú, Progress Publishers, 1973, pp. 202-209. 
Lombardo Toledano, Vicente

La doctrina socialista y su interpretación en el artículo $3^{\circ}$, México, Futuro, 1935.

Loyo, Engracia

"La política educativa de los gobiernos posrevolucionarios, 1920-1940”, en SEP, 2011.

Gobiernos revolucionarios y educación popular en México, 1911-1928, México, El Colegio de México, 1999.

"La difusión del marxismo y la educación socialista en México, 1930-1940”, en Alicia Hernández Chávez y Manuel Miño Grijalva (coords.), Cincuenta años de historia en México, México, El Colegio de México, 1993.

"Lectura para el pueblo, 1921-1940", en Historia Mexicana, XXxiII: 3 (131) (ene.-mar. 1984), pp. 289-345.

Mariátegui, José Carlos

"La crisis universitaria, crisis de maestros y crisis de ideas", en Claridad, 2 (jul. 1923).

Marsiske, Renate

Movimientos estudiantiles en la historia de América Latina, México, Universidad Nacional Autónoma de México, 2006, vol. III.

"Antecedentes del movimiento estudiantil de 1929 en la Universidad de México: actividades y organización estudiantil", en Marsiske, 2006, pp. 141-176.

Martínez Ruiz, Xicoténcatl

"Being, thinking and educating: The persistence of Vivekananda in the 20th century", en Vivekananda (2014).

"Entre Tagore y Gandhi: estudios de la juventud y pensamiento crítico", en Innovación Educativa, 12: 62 (sep.-dic. 2012). 
MCHITARJAN, Irina

"John Dewey y el desarrollo de la pedagogía rusa antes de 1930. Informe sobre una recepción olvidada”, en Encuentros sobre Educación, 10 (otoño 2009), pp. 163-186.

Melgar, Ricardo

Vivir el exilio en la ciudad, 1928. V.R. Haya de la Torre y J. A. Mella, México, Sociedad Cooperativa del "Taller Abierto", 2013.

"El epistolario como vehículo de comunicación y cultura: México en las cartas de José Carlos Mariátegui", en Pacarina del Sur. Revista de pensamiento crítico latinoamericano, consultada el 7 de febrero de 2014, http://www.pacarinadelsur. com/component/content/article/46-dossiers/dossier-10/914el-epistolario-como-vehiculo-de-comunicacion-y-culturamexico-en-las-cartas-de-jose-carlos-mariategui

Meneses Morales, Ernesto

Tendencias educativas oficiales en México, 1911-1934, México Universidad Iberoamericana, 1986.

Tendencias educativas oficiales en México, 1934-1964, México Universidad Iberoamericana, 1998.

Moraga Valle, Fabio

“'Lo mejor de Chile está ahora en México', ideas políticas y labor pedagógica de Gabriela Mistral en México, 1922-1924”, en Historia Mexicana, LxIII:3 (251) (ene.-mar. 2014), pp. 11811247.

"Guerra, liberalismo y utopía. La Sociedad Unión Americana y el primer latinoamericanismo, 1856-1867", en Palacios y PANi, 2014, pp. 419-450.

“¿Una nación íbero, latino o indoamericana? Joaquín Edwards Bello y el nacionalismo continental”, en Pita y Marichal, 2010, pp. 247-279. 
Navarro García, Abraham

"Revolución en rojo: nación, modernidad y educación socialista en El Maestro Rural: órgano de la Secretaría de Educación Pública consagrado a la educación rural (1934-1938), tesis de licenciatura, México, 2009.

Olguín García, Carolina y Jorge Saucedo

Capilla Alfonsina. La biblioteca de Alfonso Reyes. Catálogo bibliográfico, México, Fondo de Cultura Económica, 2013.

Palacios, Guillermo

La pluma y el arado. Los intelectuales pedagogos y la construcción sociocultural del "problema campesino" en México, 19321934, México, El Colegio de México, 1999.

Palacios, Guillermo y Erika PANi

Elpoder y la sangre. Guerra, Estado y nación en la década de 1860, México, El Colegio de México, 2014.

Pita, Alexandra y Carlos Marichal

Pensar el antiimperialismo. Ensayos de historia intelectual latinoamericana, México, El Colegio de México, 2010.

Preciado, Benjamín

“Las relaciones entre México y la India, 1995-2000”, en GARza E. y Chacón D; 2002, pp. 299-308.

Quintanilla, Susana

"Dioniso en México, o cómo leyeron nuestros clásicos a los clásicos griegos”, en Historia Mexicana, LI:3 (203) (ene-mar. 2002), pp. 619-663.

Rodó, José Enrique

Ariel. Motivos de Proteo, Caracas, Ayacucho, 1976.

Rolland, Romain

Vie du Tolstoi, París, 1911. 
Vida de Tolstoi, Buenos Aires, Claridad, 1924.

Vida de Vivekananda. Ensayo sobre la mística y la misión de la India militante, Buenos Aires, Librería Hachette, 1954.

Rousseau, Jean Jacques

Emilio, México, Universidad Nacional Autónoma de México, 1975, 2 volúmenes.

SÁnchez Vázquez, Adolfo

"Ideología política y literatura (Lenin ante Tolstoi)", en Cuestiones estéticas y artísticas contemporáneas, Madrid, Fondo de Cultura Económica, 1996, pp. 216-230.

ScArpa, Roque Esteban

Gabriela piensa en..., Santiago, Andrés Bello, 1978.

SEP

SEP noventa años, 1921-2011. Cimientos de la nación, México, Instituto Nacional de Antropología e Historia, 2011.

Shifman, Aleksandr Iosifovich

Tolstoi and India, Delhi, Sahitya Akademi, 1978.

Sierra, Santiago

Las misiones culturales, México, Secretaría de Educación Pública, 1973.

Sosenski, Susana

"Niños limpios y trabajadores. El teatro guiñol posrevolucionario en la construcción de la infancia mexicana", en Anuario de Estudios Americanos, 67: 2 (jul.-dic. 2010), pp. 493-518.

Swinson, Arthur

Six Minutes to Sunset: The Story of General Dyer and the Amritsar Affair, Londres, Peter Davies, 1964. 
TaвoAda, Hernán G. H.

"Oriente y el mundo clásico en José Vasconcelos", en Cuyo, Anuario de filosofía argentina y americana, 24 (2007), pp. 103-119.

TAgORE, Rabindranath

La luna nueva, nacionalismo, personalidad, sadhana, México, Secretaría de Educación Pública, 1988.

TAYLOR, Martin C.

Sensibilidad religiosa de Gabriela Mistral, Madrid, Gredos, 1975.

Thompson, Eduard John

Rabindranath Tagore: His Life and Work, Calcuta: YMCA Publishing House, 1961.

Rabindranath Tagore: Poet and Dramatist, Oxford, Oxford University Press, 1948.

Tolstoi, León

El reino de Dios está en vosotros, Madrid, Kairós, 2010.

La escuela de Yasnaia Poliana, Barcelona, JJ de Olañeta, 1978.

Torres Bodet, Jaime

Memorias, México, Porrúa, 1981.

León Tolstoi. Su vida y su obra, México, Porrúa, 1965.

“El Emilio de Rousseau”, El Maestro, 1 (1921), pp. 33-35.

Torres Septién, Valentina

Pensamiento educativo de Jaime Torres Bodet, México, Secretaría de Educación Pública, Ediciones El Caballito, 1985.

URÍAs Horcasitas, Beatriz

Historias secretas del racismo en México (1920-1950), México, Tusquets, 2007. 
VAsconcelos, José

El monismo estético, México, Cultura, Imp. Murguía, 1918. "Profesores honorarios", en Boletín de la SEP, Universidad Nacional de México, 1921.

De Robinson a Odiseo. Pedagogía estructurativa, Madrid, M. Aguilar, 1935.

Obras completas, México, Libreros Mexicanos Unidos, 1958. Memorias II, El desastre y el Proconsulado, México, Fondo de Cultura Económica, 1982.

Vinod Jalan, Rada

"Tagore: His Educational Theory", tesis de doctorado, Florida, University of Florida, 1976.

Vivekananda

Vivekananda, su visión y legado para un nuevo mundo, Delhi, ICCR, 2014.

Woldenberg, José

“Torres Bodet: carácter y trayectoria”, en Revista de la Universidad de México, 93 (nov. 2011), pp. 89-91.

Yankelevich, Pablo

"La revolución de 1910 y la utopía hispanoamericana”, en 20/10, memoria de las revoluciones en México, viI (2010), pp. 57-64.

Zweig, Stefan

Romain Rolland. El hombre y su obra, Buenos Aires, Claridad, 1946. 